\title{
Review \\ Luminescent Lifetime Regulation of Lanthanide-Doped Nanoparticles for Biosensing
}

\author{
Mingkai Wang ${ }^{1,2}$, Chuanyu $\mathrm{Hu}^{1, *}$ and Qianqian $\mathrm{Su}^{2, *(D)}$ \\ 1 Department of Stomatology, Tongji Hospital, Tongji Medical College, Huazhong University of Science and \\ Technology, Wuhan 430074, China; wmk19961108@163.com \\ 2 Institute of Nanochemistry and Nanobiology, Shanghai University, Shanghai 200444, China \\ * Correspondence: chuanyuhu@hust.edu.cn (C.H.); chmsqq@shu.edu.cn (Q.S.)
}

Citation: Wang, M.; Hu, C.; Su, Q Luminescent Lifetime Regulation of Lanthanide-Doped Nanoparticles for Biosensing. Biosensors 2022, 12, 131. https://doi.org/10.3390/ bios12020131

Received: 11 January 2022

Accepted: 12 February 2022

Published: 19 February 2022

Publisher's Note: MDPI stays neutral with regard to jurisdictional claims in published maps and institutional affiliations.

Copyright: (C) 2022 by the authors. Licensee MDPI, Basel, Switzerland. This article is an open access article distributed under the terms and conditions of the Creative Commons Attribution (CC BY) license (https:// creativecommons.org/licenses/by/ $4.0 /)$.

\begin{abstract}
Lanthanide-doped nanoparticles possess numerous advantages including tunable luminescence emission, narrow peak width and excellent optical and thermal stability, especially concerning the long lifetime from microseconds to milliseconds. Differing from other shorter-lifetime fluorescent nanomaterials, the long lifetime of lanthanide-doped nanomaterials is independent with background fluorescence interference and biological tissue depth. This review presents the recent advances in approaches to regulating the lifetime and applications of bioimaging and biodetection. We begin with the introduction of the strategies for regulating the lifetime by modulating the core-shell structure, adjusting the concentration of sensitizer and emitter, changing energy transfer channel, establishing a fluorescence resonance energy transfer pathway and changing temperature. We then summarize the applications of these nanoparticles in biosensing, including ion and molecule detecting, DNA and protease detection, cell labeling, organ imaging and thermal and $\mathrm{pH}$ sensing. Finally, the prospects and challenges of the lanthanide lifetime regulation for fundamental research and practical applications are also discussed.
\end{abstract}

Keywords: luminescence lifetime; lanthanide-doped nanoparticles; lifetime regulation; bioimaging; biodetection; biosensing

\section{Introduction}

A central goal in biology and medicine is to develop excellent imaging and detection technology [1]. Researchers have devoted massive efforts to developing fluorescence imaging technology through fluorescent nanomaterials, including quantum dots (QDs) [2], upconversion nanomaterials (UCNPs) [3], carbon-based nanomaterials [4], stoichiometric metal oxides [5], perovskite [6], metal nanomaterials [7] and other materials [8]. In addition, biological images were obtained in a non-invasive manner under laser excitation [9], which has great labeling ability, high signal strength, fast imaging speed and a wide range of applications [10-13]. However, there are numerous limitations based on conventional fluorescence imaging technology, including low sensitivity, shallow detective depth and substantial interference caused by background autofluorescence [14,15]. Among the large number of nanomaterials, lanthanide-doped nanoparticles feature a longer lifetime than other fluorescence materials, whose emission could last for milliseconds [16]. Based on these nanoparticles, lifetime imaging and detection platform were proposed to resolve the difficulty of conventional fluorescence imaging [17,18].

Unsusceptible to the concentration of nanoparticles [19], laser intensity [20] and biological tissue thickness [21], the quality of luminescence lifetime imaging is better than traditional luminescence imaging in the cell or tissue microenvironment [22]. Moreover, the sensitivity of time-gated imaging with an optical chopper offers more than one order of magnitude than that of the traditional method using optical band-pass filters [23]. The luminescence lifetime of lanthanides depends on their intrinsic properties and the localized 
microenvironment, involving $\mathrm{pH}$ value, doped ion concentration, protein interaction and other factors affecting the decay process [24]. Therefore, lifetime encoding was achieved by nanostructural engineering, while lifetime sensing was produced by changing the relying circumstances. Correspondingly, the time-resolved technology was developed rapidly due to its unique properties [25].

In this review, we focus on the recent advances in the regulating lifetime of lanthanide for biosensing and imaging (Figure 1). In Section 1, we introduce the strategies of lifetime modulation for lanthanide-doped nanoparticles, involving core-shell structure design, concentration adjusting, energy transfer channel controlling and temperature controlling. In Section 2, we discuss the use of the probes for ions and molecules, DNA and protease sensing, cell labeling, organ imaging and thermal and $\mathrm{pH}$ sensing. Finally, we discuss the prospects and challenges for possible development directions and application scenarios.

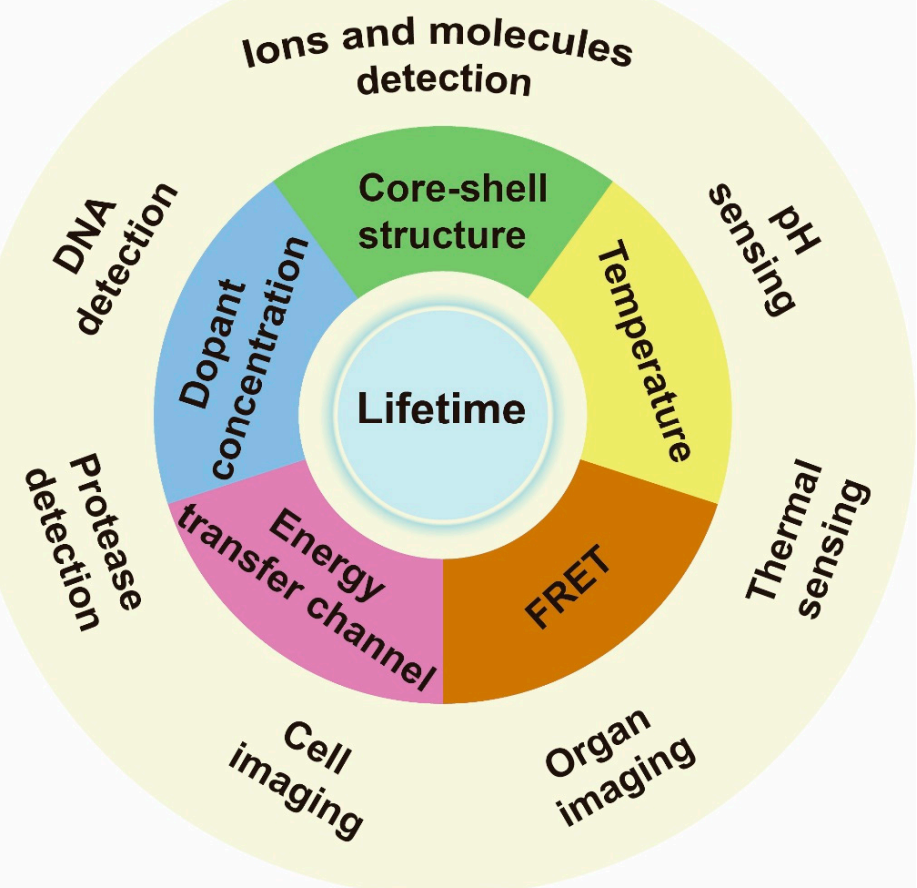

Figure 1. Schematic illustrations of lanthanide-doped nanoparticle lifetime regulation for biosensing. The approaches to regulating lifetime include varying core-shell structure, dopant concentration, energy transfer channel, temperature and setting a fluorescence resonance energy transfer (FRET) system. The relevant applications include ions, molecules, DNA, protease, thermal and $\mathrm{pH}$ sensing, as well as cell labeling and organ imaging.

\section{Lifetime Regulation}

Luminescence lifetime refers to the average time the molecule spends in the excited state returning to the ground state [26]. The lifetime of a phosphor, $\tau$, refers to the time at which the intensity decays to 1 /e of its maximum [27]. The decay of one emitting state in an upconversion energy transfer process is determined by its intrinsic decay and the intermediate states [28]. Susceptive to their intrinsic properties and local environment, the lifetime of lanthanide-doped nanoparticles could be tuned by adjusting core-shell structure, the content of sensitizer and emitter, internal energy transfer channel, FRET system and temperature. Nanocrystals with a controllable lifetime have been widely used in biosensing to eliminate background autofluorescence and light scattering interference. However, the reported methods allow only a limited range of lifetime adjustments. 


\subsection{Variation of Core-Shell Structures}

Core-shell engineering is generally utilized to reduce surface quenching effects [29]. Shell passivation could promote the upconversion process by promoting the occurrence of energy hopping in higher-lying excited states [30]. Therefore, lifetime is affected by the shell layers, including the shell thickness and shell composition.

\subsubsection{Core Size}

The defect density of core nanoparticles doped with sensitizers and emitters decreases as the nanoparticle's size increases. Jin et al. found an increase in the lifetime of $\mathrm{Yb}$, Er-doped UCNPs with the increase of their size by comparing the lifetime of these nanoparticles ranging from $6 \mathrm{~nm}$ to $45 \mathrm{~nm}$ (Figure 2a). With the assistance of a mathematical model, it was verified that the decay time was related to surface-to-volume ratio and shell thickness. In addition, the lifetime of $\beta$-phase particles has significant relationships with surface defect, solvent and vibration energy of surface ligands, while defect density only matters for $\alpha$-phase nanocrystals [31]. Liu et al. compared the decay curves of different sizes of $\mathrm{NaYF}_{4}: 20 \% \mathrm{Yb}, 2 \% \mathrm{Er}$ ranging from $15.3 \mathrm{~nm}$ to $27.2 \mathrm{~nm}$, exhibiting the increase in the lifetime of both $\mathrm{Er}^{3+}$ and $\mathrm{Yb}^{3+}$ at $540 \mathrm{~nm}$ and $985 \mathrm{~nm}$, respectively, as the nanoparticle dimension expanded [32].

\subsubsection{Inert Shell Passivation}

The epitaxial shell could protect the excitation energy from trapping by surface ligands or solvent molecules, leading to a long-lived lifetime. Su et al. designed a core-shellshell heterostructure to prolong the lifetime of upconversion emitters. An optically inert $\mathrm{NaYF}_{4}$ shell on the surface of $\mathrm{NaGdF}_{4} @ \mathrm{NaGdF}_{4}$ core-shell nanoparticle could efficiently block the energy transfer from $\mathrm{Gd}^{3+}$ to surface quenchers, thereby promoting efficient upconversion emission and long lifetimes of $\mathrm{Gd}^{3+}$ [33]. Mao et al. successively compared the decay curves of $\mathrm{NaYF}_{4}: \mathrm{Yb} / \mathrm{Er} / \mathrm{Mn}\left(\mathrm{C}_{\mathrm{d}}\right), \mathrm{NaYF}_{4} @ \mathrm{NaYF}_{4}: \mathrm{Yb} / \mathrm{Er} / \mathrm{Mn}\left(\mathrm{C} / \mathrm{S}_{\mathrm{d}}\right), \mathrm{NaYF}_{4}$ : $\mathrm{Yb} / \mathrm{Er} / \mathrm{Mn} @ \mathrm{NaYF}_{4}\left(\mathrm{C}_{\mathrm{d}} / \mathrm{S}\right)$ and $\mathrm{NaYF}_{4} @ \mathrm{NaYF}_{4}: \mathrm{Yb} / \mathrm{Er} / \mathrm{Mn} @ \mathrm{NaYF}_{4}\left(\mathrm{C} / \mathrm{S}_{\mathrm{d}} / \mathrm{S}\right)$, finding the lifetime became longer. Amongst them, the $\mathrm{C} / \mathrm{S}_{\mathrm{d}} / \mathrm{S}$ structure has two layers of $\mathrm{NaYF}_{4}$ interface contacting the active shell, which reduced surface defects and thus enhanced the upconversion process. Therefore, the lifetime can be prolonged by reducing energy defects and increasing the energy transfer rate [34].

$\mathrm{CaF}_{2}$ is a biocompatible and fluoride-rich matrix that is well used as a shell in upconversion nanomaterials, which can simultaneously suppress the interfacial diffusion of $\mathrm{Ln}^{3+}$ and surface quenching [35]. After heterogenous $\mathrm{CaF}_{2}$ layer was coated on the $\mathrm{NaGdF}_{4}$ : $\mathrm{Yb}$,Er, the lifetime of $\mathrm{Er}^{3+}$ at $532 \mathrm{~nm}$ prolonged from $89 \mu \mathrm{s}$ to $162 \mu \mathrm{s}$, accompanied by the green $\left({ }^{2} \mathrm{H}_{11 / 2},{ }^{4} \mathrm{~S}_{3 / 2} \rightarrow{ }^{4} \mathrm{I}_{15 / 2}\right)$ and red $\left({ }^{4} \mathrm{I}_{15 / 2} \rightarrow{ }^{4} \mathrm{I}_{15 / 2}\right)$ emissions of $\mathrm{Er}^{3+}$ enhanced 24.2 and 55.5 times, respectively [36]. When $\mathrm{CaF}_{2}$ grew on the core of $\mathrm{NaYF}_{4}: 10 \% \mathrm{Yb}, 30 \% \mathrm{Nd}$, the lifetime of $\mathrm{Yb}^{3+}$ at $1000 \mathrm{~nm}$ increased from $51 \mu$ s up to $833 \mu \mathrm{s}$, indicating the surface lattice defects were minimized [37].

Interestingly, $\mathrm{Su}$ et al. provided an upconverted excitation lock-in (UCEL) mode to block the energy consumption of $\mathrm{Gd}^{3+}$ caused by lattice defects and impurities. $\mathrm{NaYF}_{4-}$ based interlayer can effectively suppress the energy loss within the nanoparticles induced by inner lattice defects and promote energy recycling in the core domain. Therefore, the lifetime and the emission intensity of the heterogeneous structure significantly increased compared with the homogeneous counterparts (Figure 2b) [38].

Increasing shell thickness could suppress the non-radiative effect and cross-relaxation. Liu et al. synthesized $\mathrm{NaYF}_{4}: \mathrm{Yb}^{3+}, \mathrm{Er}^{3+} @ \mathrm{mNaYF}_{4}(\mathrm{~m}=0,1,2,3,4,5)$ core-shell nanoparticles with different shell thicknesses $(7.5 \mathrm{~nm}, 9 \mathrm{~nm}, 10 \mathrm{~nm}, 11 \mathrm{~nm}, 11.8 \mathrm{~nm}$ and $16.5 \mathrm{~nm})$. The corresponding lifetimes of these nanoparticles were measured to be $10.10 \mu \mathrm{s}, 11.57 \mu \mathrm{s}$, $15.78 \mu \mathrm{s}, 19.77 \mu \mathrm{s}, 23.51 \mu \mathrm{s}$ and $26.52 \mu \mathrm{s}$ due to the protection of shell [39]. Furthermore, increasing heterogenous shell thickness could minimize surface quenching. Coating a $\mathrm{CaF}_{2}$ shell with a range of thickness from $0 \mathrm{~nm}$ to $5.3 \mathrm{~nm}$ on the $\mathrm{NaYbF}_{4}$, the lifetime of $\mathrm{Yb}^{3+}$ of $980 \mathrm{~nm}$ increased from $33 \mu$ s to $2.18 \mathrm{~ms}$, excited at $920 \mathrm{~nm}$ measured by an optical 
parametric oscillator (OPO) laser. Therein, when the $\mathrm{CaF}_{2}$ shell thickness reached $2.6 \mathrm{~nm}$, the luminescence lifetime value was approximate to the radiative lifetime of $\mathrm{Yb}^{3+}$ [40].

\subsubsection{Active Shell}

With regard to the active shell, Liu et al. proved that increasing the concentration of sensitizer in the shell had adverse impacts on the luminescence intensity and lifetime enhancement. In a NaYF $4: 20 \% \mathrm{Yb}, 2 \% \mathrm{Er} @ \mathrm{NaYF}_{4}: \mathrm{m} \% \mathrm{Yb}(\mathrm{m}=0,10,20)$ nanoparticle, the lifetime of $\mathrm{Er}^{3+}$ and $\mathrm{Yb}^{3+}$ at $540 \mathrm{~nm}$ and $985 \mathrm{~nm}$ decreased when the concentration of $\mathrm{Yb}^{3+}$ in the shell increased. This can be attributed to the fact that more sensitizers in the shell increased the possibility of energy trapped by the surface defect. In addition, a lower energy transfer efficiency was observed due to the longer distance between sensitizer and emitter compared with that in the counterpart consisting of inner sensitizers [32].

A longer migration distance imparted by thicker energy migration layers or an increased number of migration steps may prolong luminescence lifetime. In a core/multishell $\mathrm{NaYF}_{4} @ \mathrm{NaYbF}_{4} @ \mathrm{NaYF}_{4}: \mathrm{Yb}^{3+} / \mathrm{Tm}^{3+} @ \mathrm{NaYF}_{4}$ nanoparticle, the thickness of the energy migration layer $\left(\mathrm{NaYbF}_{4}\right)$ increased from $0,1.5,3.0,5.0$ to $8.0 \mathrm{~nm}$ gradually, and the lifetime at $808 \mathrm{~nm}$ increased from 867, 1027, 1162, 1201 to $1282 \mu \mathrm{s}$, respectively [41]. When the thickness of the shell doped with sensitizers (i.e., $\mathrm{Yb}^{3+}$ ) increased, the lifetime of activators was longer in the core due to $\mathrm{Yb}$ energy migration. Increasing the thickness of the second layer

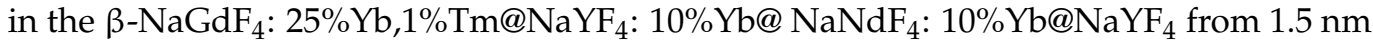
to $5.4 \mathrm{~nm}$, the lifetime at $475 \mathrm{~nm}$ prolonged from $632 \mu$ s to $836 \mu$ s [42]. In addition, with $\mathrm{NaGdF}_{4} @ \mathrm{NaGdF}_{4}: \mathrm{Yb}$,Er@NaYF $4: \mathrm{Yb}_{\mathrm{NaNdF}}: \mathrm{Yb}$ used as an experimental model, the lifetime at $1525 \mathrm{~nm}$ was enhanced when increasing the thickness of the energy relay layer $\left(\mathrm{NaYF}_{4}: \mathrm{Yb}\right)$, which was attributed to the enlarged distance from sensitizers to emitters. A similar trend was also observed in $\mathrm{Ho}^{3+}$-doped nanoparticles (Figure 2c). Meanwhile, a certain $\mathrm{Yb}^{3+}$-doped shell thickness corresponded to the determined capacity of $\mathrm{Yb}^{3+}$ sublattice. Therefore, increasing the concentration of emitters could accelerate the stored energy into luminescence emission, resulting in a shortened lifetime. As the proportion of $\mathrm{Er}^{3+}$ rose from $0.5 \%$ up to $32 \%$, the lifetime at $540 \mathrm{~nm}$ decreased from $101 \mu$ s to $13 \mu$ s [43].

\subsection{Changing Concentration of Sensitizer and Emitter}

Excessive emitters would increase the probability of cross-relaxation, leading to concentration quenching. For a $\mathrm{Yb}^{3+}-\mathrm{Er}^{3+}-\mathrm{Ho}^{3+}$ tri-doped nanoparticle, higher content of $\mathrm{Ho}^{3+}$ could shorten the interionic distances of $\mathrm{Yb}^{3+}-\mathrm{Er}^{3+} / \mathrm{Ho}^{3+}, \mathrm{Er}^{3+}-\mathrm{Ho}^{3+}$ and $\mathrm{Ho}^{3+}-\mathrm{Ho}^{3+}$, which could enhance the non-radiative process and energy transfer (ET) sensitization. A decrease in the lifetime of $\mathrm{Ho}^{3+}(643 \mathrm{~nm}, 750 \mathrm{~nm}, 895 \mathrm{~nm}), \mathrm{Er}^{3+}(525 \mathrm{~nm}, 545 \mathrm{~nm}, 655 \mathrm{~nm}, 810 \mathrm{~nm}$, $845 \mathrm{~nm})$ and $\mathrm{Yb}^{3+}(1020 \mathrm{~nm})$ was observed when increasing the concentration of $\mathrm{Ho}^{3+}$ [44]. Similarly, as the mole content of $\mathrm{Tm}^{3+}$ rose from $0.2 \%$ to $8 \%$ in $\mathrm{NaYF}_{4}: 20 \% \mathrm{Yb}, \mathrm{x} \% \mathrm{Tm}$ $(40 \mathrm{~nm})$, the lifetime of the blue emission was reduced from $662.4 \mu$ s to $25.6 \mu$ s (Figure 3a). Meanwhile, as the mole percentage of $\mathrm{Yb}^{3+}$ rose from $10 \%$ to $30 \%$ in $\mathrm{NaYF}_{4}: \mathrm{x} \% \mathrm{Yb}, 1 \% \mathrm{Tm}$, the lifetime of the same blue emission decreased from $206.7 \mu$ s to $120.2 \mu$ s [20]. The higher concentration of part of emitters would likely cause self-aggregation and cross relaxation, resulting in a shortened lifetime. When the $\mathrm{Er}^{3+}$ concentration was varying from $1 \%$ to $70 \%$ in the $\beta-\mathrm{NaYbF}_{4} @ \mathrm{NaY}_{0.8-x} \mathrm{Er}_{x} \mathrm{Gd}_{0.2} \mathrm{~F}_{4} @ \mathrm{NaY}_{0.8} \mathrm{Gd}_{0.2} \mathrm{~F}_{4}$, the lifetime of $\mathrm{Er}^{3+}$ at the level of ${ }^{4} S_{3 / 2}(540 \mathrm{~nm})$ decreased sequentially. The shorter lifetime was attributed to the noneffective passivation on the surface when dopant with a higher concentration of emitters. Due to the greater energy from $\mathrm{Yb}^{3+}\left({ }^{2} \mathrm{~F}_{5 / 2}\right)$ being transferred to $\mathrm{Er}^{3+}\left({ }^{4} \mathrm{~S}_{3 / 2},{ }^{4} \mathrm{~S}_{9 / 2}\right)$, the lifetime of $\mathrm{Yb}^{3+}$ was shortened. With the lack of cross-relaxation pathways for the ${ }^{4} \mathrm{~S}_{9 / 2}$ level of $\mathrm{Er}^{3+}$, the lifetime rarely has significant changes with the $\mathrm{Er}^{3+}$ concentration variation. Interestingly, the lifetime of $\mathrm{Er}^{3+}$ at $654 \mathrm{~nm}$ in the $\beta-\mathrm{NaYbF}_{4} @ \mathrm{NaY}_{0.8-x} \mathrm{Er}_{x} \mathrm{Gd}_{0.2} \mathrm{~F}_{4}$ structure had a long lifetime due to more incredible energy transferring to the surface [45]. 
(a)

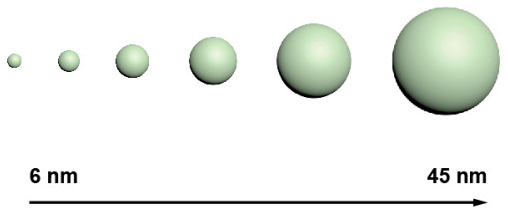

$\mathrm{NaYF}_{4}: \mathrm{Yb} / \mathrm{Er}$

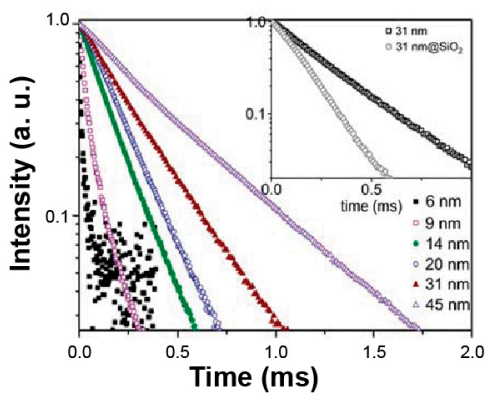

(b)
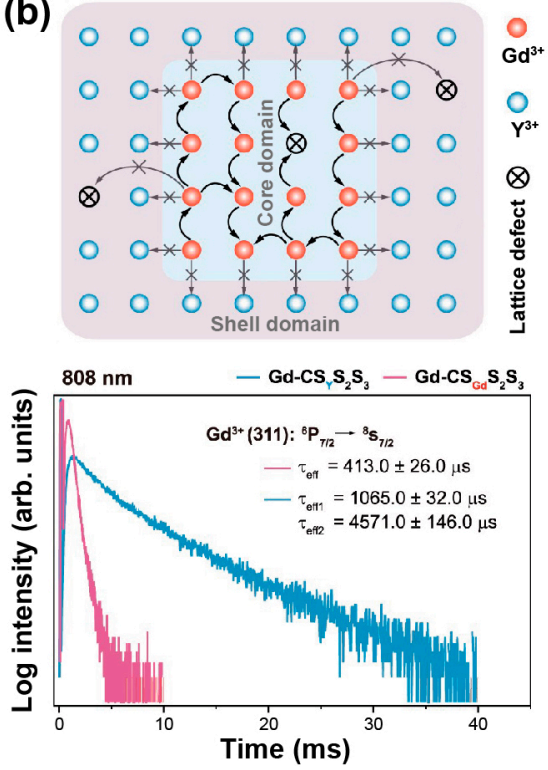
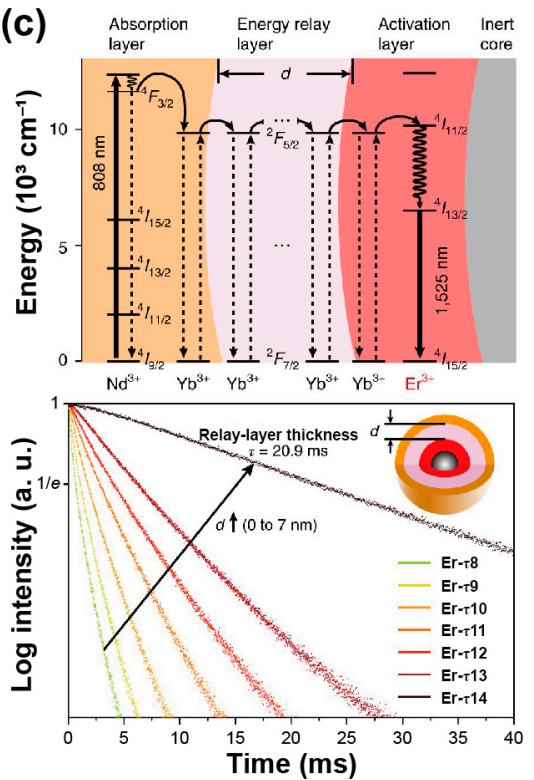

Figure 2. (a) The schematic description for the size of $\mathrm{NaYF}_{4}$ : $\mathrm{Yb}$,Er nanoparticles and lifetime decay curves of green emission in these nanoparticles. Reproduced with permission from [31]. Copyright 2013, Royal Society of Chemistry. (b) The diagram of energy transfer mechanism in $\mathrm{NaGdF}_{4}$ : $49 \% \mathrm{Yb}, 1 \% \mathrm{Tm}$ coated with heterogeneous shell nanoparticle, and corresponding lifetimes of $\mathrm{Gd}^{3+}$ in homogenerous and heterogeneous nanoparticles at $310 \mathrm{~nm}$ under $808 \mathrm{~nm}$ excitation. Reproduced with permission from [38]. Copyright 2021, Nature Publishing Group. (c) The diagrammatic drawing of energy transfer process in the core-multishell nanoparticles and luminescence decay curves at $1525 \mathrm{~nm}$ with the energy relay shell thickness ranging from $0 \mathrm{~nm}$ to $7 \mathrm{~nm}$. Reproduced with permission from [43]. Copyright 2018, Nature Publishing Group.

Simultaneous excitation of two $\mathrm{Yb}^{3+}$ ions can produce $\mathrm{Yb}^{3+}$ dimers with higher excitation energy, which could upconvert photons to $\mathrm{Tb}^{3+}$. To study the composition-dependent emission lifetimes and the effect on the energy transfer efficiency, Yan et al. employed the $\mathrm{Tb}^{3+}-\mathrm{Yb}^{3+}-\mathrm{Nd}^{3+}$ co-doped $\mathrm{NaGdF}_{4}: 80 \% \mathrm{Yb}, 10 \% \mathrm{~Tb} @ \mathrm{NaGdF}_{4}: 50 \% \mathrm{Nd}, 10 \% \mathrm{Yb}$ nanoparticles with varied doping concentrations as the study model. The lifetime of $\mathrm{Tb}^{3+}$ reached $1.76 \mathrm{~ms}$ when the content of $\mathrm{Yb}^{3+}$ rose from $20 \%$ to $80 \%$ because more $\mathrm{Yb}^{3+}$ facilitated the formation of $\mathrm{Yb}^{3+}$ dimer. The lifetime at $542 \mathrm{~nm}$ is slightly prolonged by $0.06 \mathrm{~ms}$ when the proportion of $\mathrm{Tb}^{3+}$ increased from $5 \%$ to $10 \%$ due to promoted energy transfer from $\mathrm{Yb}^{3+}$ dimer to $\mathrm{Tb}^{3+}$. In addition, when the content of $\mathrm{Nd}^{3+}$ increased from $10 \%$ to $50 \%$, near-infrared absorption intensity improved, the lifetime of $\mathrm{Tb}^{3+}$ at $542 \mathrm{~nm}$ and $\mathrm{Yb}^{3+}$ at $1000 \mathrm{~nm}$ both increased, indicating more energy was transferred to $\mathrm{Tb}^{3+}$ and $\mathrm{Yb}^{3+}[46]$.

A constant lifetime can be obtained when the doping content of the sensitizer is changed. To investigate the relationship between lifetime decay behavior and luminescence emission intensity, core-shell structure of $\mathrm{NaYF}_{4} @ \mathrm{NaYF}_{4}: \mathrm{x} \% \mathrm{Yb}, 1 \% \mathrm{Tm} @ \mathrm{NaYF}_{4}$ : $\mathrm{y} \% \mathrm{Yb} @ \mathrm{NaYF}_{4}$ nanoparticles was developed by Zhang et al. Changing the mole content of $\mathrm{Yb}^{3+}$ in the first shell from $20 \%$ up to $80 \%$, the emissive intensity changed while the luminescence lifetime at $475 \mathrm{~nm}$ kept constant, suggesting a constant lifetime with different emissive intensity could be obtained. When the concentration of $\mathrm{Yb}^{3+}$ in the first and second shell layers was changed, the varied lifetime (1256 ms to $310 \mathrm{~ms}$ ) was obtained with a constant emission intensity (Figure $3 b$ ) [47]. For the mentioned nanoparticles, the declined $\mathrm{Yb}^{3+}$ concentration increased the mean value of the distance between $\mathrm{Yb}^{3+}$ and $\mathrm{Tm}^{3+}$ ions, leading to a longer lifetime due to the weakened back energy transfer process. The $\mathrm{Yb}^{3+}$ concentration in the energy transfer upconversion layers was decreased from $99 \%, 70 \%, 50 \%, 40 \%, 20 \%$ to $10 \%$, resulting in the lifetime at $808 \mathrm{~nm}$ being increased from $1282,1315,1481,1618,1721$ to $2157 \mu \mathrm{s}$, respectively [41]. Besides, the $\mathrm{Tm}^{3+}$ could be served as sensitizers and transfer energy to $\mathrm{Yb}^{3+}, \mathrm{Ho}^{3+}$ and $\mathrm{Er}^{3+}$ when excited at $808 \mathrm{~nm}$ and 
$1208 \mathrm{~nm}$, respectively. The lifetime of $\mathrm{Yb}^{3+}(980 \mathrm{~nm}), \mathrm{Ho}^{3+}(1180 \mathrm{~nm})$ and $\mathrm{Er}^{3+}(1525 \mathrm{~nm})$ decreased with the increase of the $\mathrm{Tm}^{3+}$ molar ratio [48].

(a)

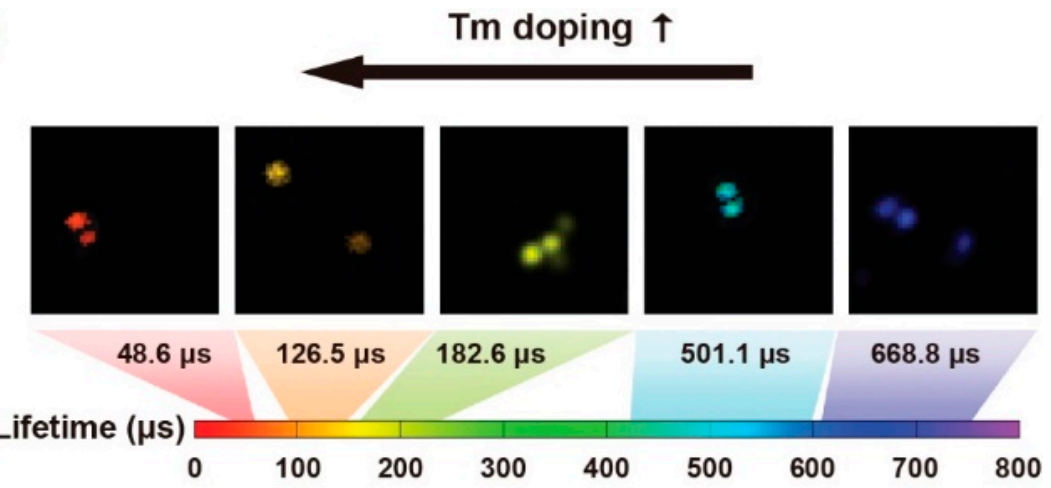

(b)

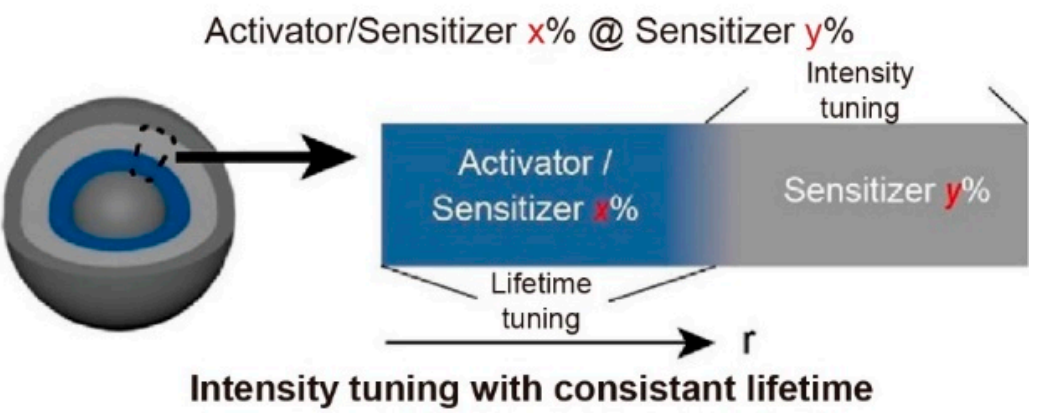

Figure 3. (a) The time-resolved confocal images of $\mathrm{NaYF}_{4}$ : $\mathrm{Yb}$, Tm nanoparticles and the lifetime tuning scheme by changing $\mathrm{Tm}^{3+}$ doping concentrations. Reproduced with permission from [20]. Copyright 2014, Nature Publishing Group. (b) Diagrammatic illustration of consistent lifetime with tunable intensity by doping various sensitive gradients in the shell. Reproduced with permission from [47]. Copyright 2021, WILEY-VCH.

\subsection{Adjusting the Energy Transfer Channel}

The decay process of an excited state is inversely proportional to the energy transfer rate and the radiative and non-radiative transition rates. Tri-doped nanoparticles of $\mathrm{NaYF}_{4} @ \mathrm{NaYF}_{4}: \mathrm{Er}^{3+} / \mathrm{Yb}^{3+} / \mathrm{Mn}^{2+} @ \mathrm{NaYF}_{4}$ were synthesized by Mao et al., exhibiting the new energy transfer process between $\mathrm{Mn}^{2+}$ and $\mathrm{Er}^{3+}$. With a non-radiative energy transfer channel created between the level of $\mathrm{Mn}^{2+}\left({ }^{4} \mathrm{~T}_{1}\right)$ and $\mathrm{Er}^{3+}\left({ }^{2} \mathrm{H}_{11 / 2}\right.$ and $\left.{ }^{4} \mathrm{~S}_{3 / 2}\right)$, the overall transition rate increased owing to the resonance energy transfer, leading to a reduced lifetime of $\mathrm{Er}^{3+}$ at $550 \mathrm{~nm}$. The presence of $\mathrm{Mn}^{2+}$ ions promoted the relaxation of the ${ }^{4} \mathrm{~S}_{3 / 2}$ energy level, and the red emission of $\mathrm{Er}^{3+}$ increased with the shortening of the decay time. Therefore, the increased population density of $\mathrm{Mn}^{2+}$ caused the decreased radiative transition rate of $\mathrm{Er}^{3+}\left({ }^{4} \mathrm{~S}_{3 / 2}\right.$ and $\left.{ }^{2} \mathrm{H}_{11 / 2}\right)$ turning down to ground state, resulting in an enhancement of red emission due to energy transfer from $\mathrm{Mn}^{2+}\left({ }^{4} \mathrm{~T}_{1}\right)$ to $\mathrm{Er}^{3+}\left({ }^{4} \mathrm{~F}_{9 / 2}\right)$ (Figure 4a). Meanwhile, the increased lifetime of $\mathrm{Er}^{3+}$ at $650 \mathrm{~nm}$ also verified the role of $\mathrm{Mn}^{2+}$ in energy transfer trace according to the decay curves of various content of $\mathrm{Mn}^{2+}(0 \%$, $10 \%, 20 \%, 30 \%$ ) (Figure $4 b$ ) [34].

Introducing transition metal ions with a long lifetime into conventional UCNPs is particularly attractive. The lifetime of $\mathrm{Mn}^{2+}$ ions could be modulated by crystal-site engineering. Liu et al. tuned the luminescence properties of $\mathrm{Mn}^{2+}$ in core-multishell nanoparticles by doping $\mathrm{Ca}^{2+}$ or $\mathrm{Mg}^{2+}$, changing the output color from green to yellow and prolonging its lifetime [49]. The spin-forbidden transition of $\mathrm{Mn}^{2+}$ occurs between ${ }^{4} \mathrm{~T}_{1} \rightarrow{ }^{6} \mathrm{~A}_{1}$, allowing a longer fluorescence lifetime than lanthanide emitters. Because of the larger energy mismatch between $\mathrm{Yb}^{3+}$ and $\mathrm{Mn}^{2+}$, the $\mathrm{Yb}^{3+}-\mathrm{Mn}^{2+}$ dimer is difficult to form. However, Zhang et al. reported the successful preparation of $\mathrm{Yb}^{3+}-\mathrm{Mn}^{2+}$ dimers, 
obtaining a substantial long lifetime of $\mathrm{Eu}^{3+}(91 \mathrm{~ms})$, while the normal UC lifetime of $\mathrm{Eu}^{3+}$ is only about $7 \mathrm{~ms}$. In addition, there is a dynamic population balance between the energy state $\left|{ }^{2} \mathrm{~F}_{7 / 2},{ }^{4} \mathrm{~T}_{1}(4 \mathrm{G})\right\rangle\left(\mathrm{Yb}^{3+}-\mathrm{Mn}^{2+}\right.$ dimers $)$ and ${ }^{5} \mathrm{D}_{0}\left(\mathrm{Eu}^{3+}\right)$, causing the sustained energy transferring from $\mathrm{Yb}^{3+}-\mathrm{Mn}^{2+}$ dimers to $\mathrm{Eu}^{3+}[50]$.

The long-lived $\mathrm{Mn}^{2+}$ integrated with the short-lived lanthanide particle platform could establish a new energy transfer pathway, and then affect the whole decay process. In a $\mathrm{NaGdF}_{4}: 30 \% \mathrm{Mn} @ \mathrm{NaGdF}_{4}: 49 \% \mathrm{Yb}, 1 \% \mathrm{Tm} @ \mathrm{NaYF}_{4}$ nanoparticle, Gd sublattice-mediated energy migration facilitates $\mathrm{Mn}^{2+}$ upconversion luminescence, leading to a decrease in the lifetime of $\mathrm{Gd}^{3+}$ at $311 \mathrm{~nm}\left({ }^{6} \mathrm{P}_{7 / 2} \rightarrow{ }^{8} \mathrm{~S}_{7 / 2}\right)$ from 6.5 to $4 \mathrm{~ms}$ (Figure 4c) [51]. As a result, the lifetime of lanthanide ions may be affected when the external ions introduced and interfered with the energy transfer channels.

(a)

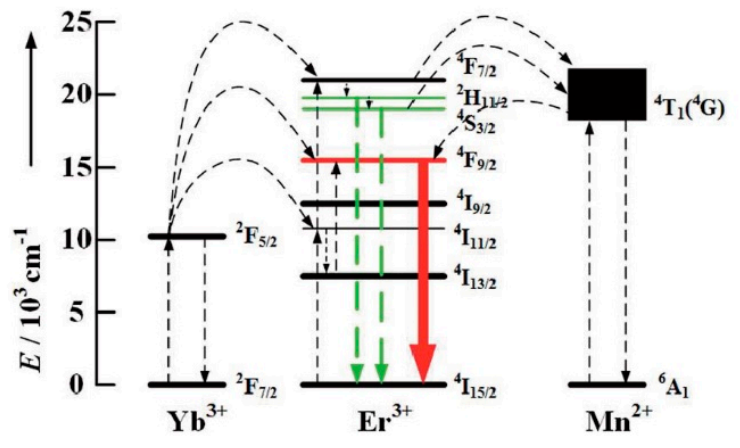

(b)
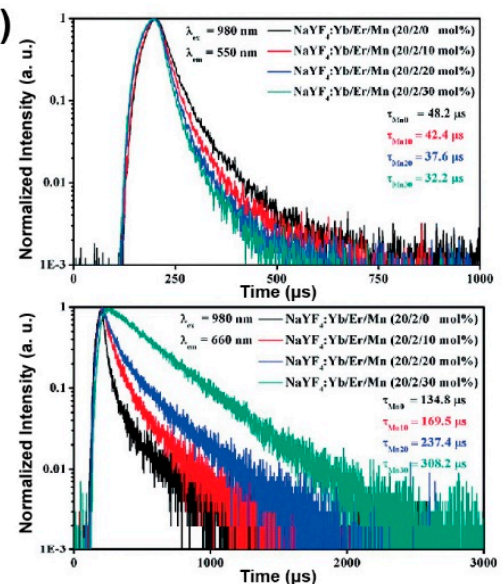

Long-lived upconversion core upconversion shells

(c)

Long-lived upconversion core

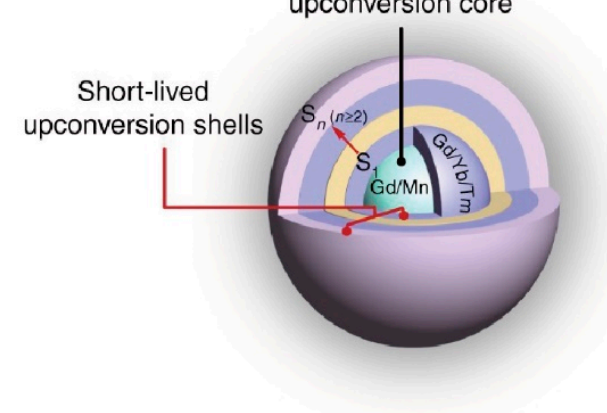

Figure 4. (a) The diagram for energy transfer mechanism among $\mathrm{Yb}^{3+}, \mathrm{Er}^{3+}$ and $\mathrm{Mn}^{2+}$ under $980 \mathrm{~nm}$ excitation. (b) Luminescence decay curves of $\mathrm{Er}^{3+}$ at $550 \mathrm{~nm}$ and $650 \mathrm{~nm}$ in $\mathrm{NaYF}_{4}: \mathrm{Yb}^{3+} / \mathrm{Er}^{3+}$ nanoparticles with different $\mathrm{Mn}^{2+}$ concentrations $(0,10,20$ and $30 \mathrm{~mol} \%)$. Reproduced with permission from [34]. Copyright 2016, Royal Society of Chemistry. (c) Structural design of core-multishell nanoparticle and the energy transfer pathway among the $\mathrm{Yb}^{3+}, \mathrm{Tm}^{3+}, \mathrm{Gd}^{3+}$ and $\mathrm{Mn}^{2+}$ ions for the short- and long-lived upconversion luminescence under $980 \mathrm{~nm}$ excitation. Reproduced with permission from [51]. Copyright 2017, Nature Publishing Group.

Doping various amounts of $\mathrm{Gd}^{3+}$ into the $\mathrm{NaYF}_{4}$ host nanocrystals could regulate the upconversion photoluminescence lifetimes. Xie et al. prolonged the lifetime of $\mathrm{Er}^{3+}$ $\left({ }^{4} \mathrm{~S}_{3 / 2} \rightarrow{ }^{4} \mathrm{I}_{15 / 2},{ }^{4} \mathrm{~F}_{9 / 2} \rightarrow{ }^{4} \mathrm{I}_{15 / 2}\right)$ by utilizing the $\mathrm{Gd}^{3+}$, substituting for $\mathrm{Y}^{3+}$ and $\mathrm{Yb}^{3+}$ in the crystal lattice of $\mathrm{NaYF}_{4}$ host, which attributed to the energy transfer rate decrease caused by the average sensitizer-activator separation increasing [52].

\subsection{Fluorescence Resonance Energy Transfer}

An efficient energy transfer pathway could be established in fluorescence dye-loaded rare-earth nanocrystals, which enables luminescence lifetime tuning [53]. In contrast to 
conventional molecular donor-acceptor pairs, the energy transfer efficiency is related to the distances between lanthanide-doped nanoparticles, and thus significantly depends on the nanoparticle diameter. Hirsch et al. synthesized $\mathrm{NaYF}_{4}: 20 \% \mathrm{Yb}, 2 \% \mathrm{Er}$ with the precisely controlled size spanning from 10 to $43 \mathrm{~nm}$, and coated with sulforhodamine B and rose bengal by ligand exchange. The nanoparticles with a mean diameter ranging from 20 to $25 \mathrm{~nm}$ possessed an optimum efficiency of $50-60 \%$. The lifetime of $\mathrm{Er}^{3+}$ at $600 \mathrm{~nm}$ decreased primarily due to the competition of non-radiative surface deactivation at the smaller surface-to-volume ratios (Figure 5a) [54]. Li et al. loaded the IR-820 on $\mathrm{NaYF}_{4}$ : Tm to construct a FRET system. Luminescence decay from ${ }^{3} \mathrm{H}_{6} \rightarrow{ }^{3} \mathrm{H}_{4}$ transition was used as a detection signal. When the energy accepter (IR-820) was attached to the donor $\left(\mathrm{Tm}^{3+}:{ }^{3} \mathrm{H}_{4}\right)$ under $785 \mathrm{~nm}$ excitation, the lifetime of $\mathrm{Tm}^{3+}$ at $800 \mathrm{~nm}$ decreased because of luminescence resonance energy transfer (Figure 5b) [55]. Su et al. loaded the IR-806 on the $\mathrm{NaGdF}_{4}: 49 \% \mathrm{Yb}, 1 \% \mathrm{Tm}_{\mathrm{N}} @ \mathrm{NaYF}_{4}: 20 \% \mathrm{Yb} @ \mathrm{NaGdF}_{4}: 50 \% \mathrm{Nd}, 10 \% \mathrm{Yb} @ \mathrm{NaGdF}_{4}$ nanoparticles to improve the ultraviolet luminescence intensity. With the back energy transferred from the nanoparticles to dye molecules, the decreased lifetimes of $\mathrm{Gd}^{3+}$ and $\mathrm{Tm}^{3+}$ ions were observed at 253, 276, 290, 310, 360 and $475 \mathrm{~nm}$ [56]. An organic fluorescent dye as an antenna could be used to broaden and increase absorption for UCNPs, allowing the energy to flow to dye molecules. Meanwhile, the hybrid system between dye molecules and UCNPs creates a new energy diffusion pathway, increasing the radiative transition process. Li et al. added the $\mathrm{Cy} 3-\mathrm{SO}_{3}$ into a $\mathrm{NaYF}_{4}: 20 \% \mathrm{Yb}, 2 \% \mathrm{Er} @ \mathrm{CaF}_{2}$ solution to construct an energy dissipation channel, which could transfer energy to the dye by the radiative transition. As a result, the luminescence lifetime of $\mathrm{Er}^{3+}$ at $488 \mathrm{~nm}$ decreased with the concentration of $\mathrm{Cy}_{3}-\mathrm{SO}_{3}$ increase $(0.67,2,4$, and $5.33 \mu \mathrm{M})$. The reduced lifetime value verified the non-radiative energy transfer process between $\mathrm{Er}^{3+}$ and $\mathrm{Cy}_{3}-\mathrm{SO}_{3}$ [57].

The triplet excitons could be trapped by inter- or intra-molecular interactions and prolong organic phosphorescence. For example, $\mathrm{Yb}^{3+}$ luminescence could be generated by organic $\mathrm{Yb}^{3+}$ complexes and hybrid organic-conjugated $\mathrm{Yb}^{3+}$-doped nanoparticles. Ye et al. prepared a composite thin film, in which the $\mathrm{Yb}^{3+}$ ions are incorporated with tetrakis(pentafluorophenyl)imidodiphosphinate to form the $\mathrm{Yb}(\mathrm{F}-\mathrm{TPIP})_{3}$ chelate, while zinc salt of 2-(tetrafluoro-2-hydroxyphenyl)tetrafluorobenzothiazole $\left(\mathrm{Zn}(\mathrm{F}-\mathrm{BTZ})_{2}\right)$ served as the organic chromophore. The $\mathrm{Zn}(\mathrm{F}-\mathrm{BTZ})_{2}$ possessed the emission ranging from $450 \mathrm{~nm}$ to $900 \mathrm{~nm}$ under $405 \mathrm{~nm}$ excitation, and gave rise of the $\mathrm{Yb}^{3+}$ emission centered at $975 \mathrm{~nm}$ from the transition of $\mathrm{Yb}^{3+}:{ }^{2} \mathrm{~F}_{5 / 2} \rightarrow{ }^{2} \mathrm{~F}_{7 / 2}$. Note that the intrinsic lifetime of $\mathrm{Yb}^{3+}$ at $1 \mu \mathrm{m}$ is about $\sim 1 \mathrm{~ms}$. The lifetime of sensitized organic $\mathrm{Yb}^{3+}$ compounds could prolong up to $\sim 0.3 \mathrm{~s}$. The prolonged emission lifetime was demonstrated by dynamic equilibrium due to the energy transfer process from long-lived organic triplet excitons [58].

The surface ligand coordination could reconstruct the crystal-field splitting and orbital hybridization, and narrow the gap of the $4 \mathrm{~d}$ orbitals between inner and surface lanthanide sensitizers. For example, after the bidentate picolinic acid (2PA) molecules coordinated to $\mathrm{NaGdF}_{4}: \mathrm{Yb}$ nanoparticles, a longer lifetime $(289 \mu \mathrm{s})$ at $980 \mathrm{~nm}$ was observed. The results confirmed that 2PA molecules could activate the dark surface layers and facilitate energy migration in the $\mathrm{Yb}^{3+}$ sublattices. The $\mathrm{Yb}^{3+}-2 \mathrm{PA}$ coupling facilitated energy migration by $4 \mathrm{f}$-orbital energy resonance within the ytterbium sublattice, which can reduce surface defects to hinder energy diffusion. Density functional theory (DFT) verified that 2PA coating could narrow the gap between the superficial and inner $\mathrm{Yb}^{3+}$ by lowering the empty $4 \mathrm{f}$ levels. Rigid ligands also stabilized the excited state of superficial $\mathrm{Yb}^{3+}$, prevented the superficial lanthanide ions from the solvent and fluoride vacancy-induced quenching, and thus significantly suppressing multiphonon non-radiative decay (Figure 5c) [59]. 
(a)

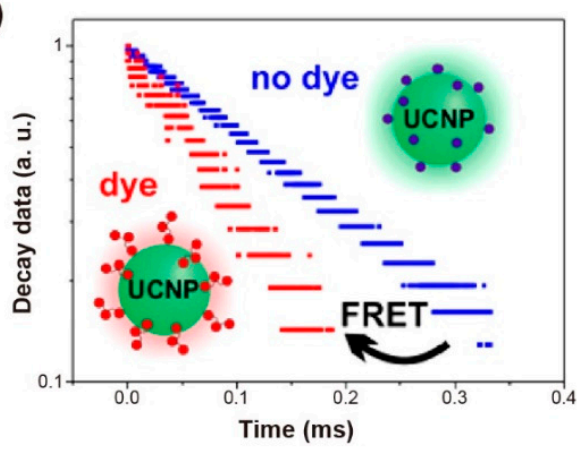

(b)

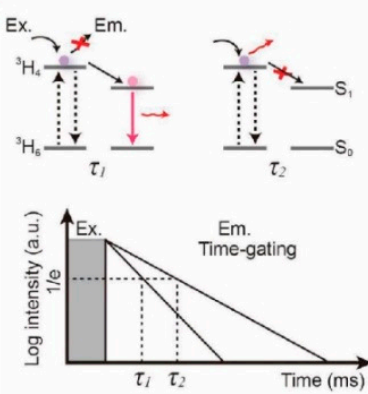

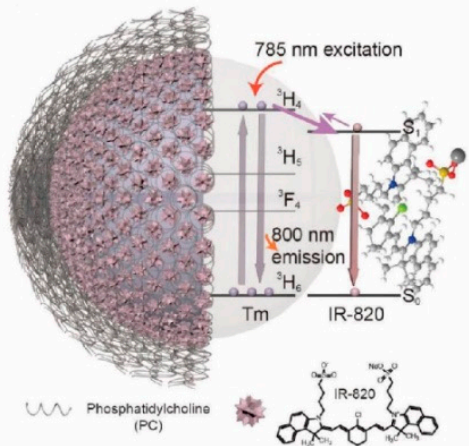

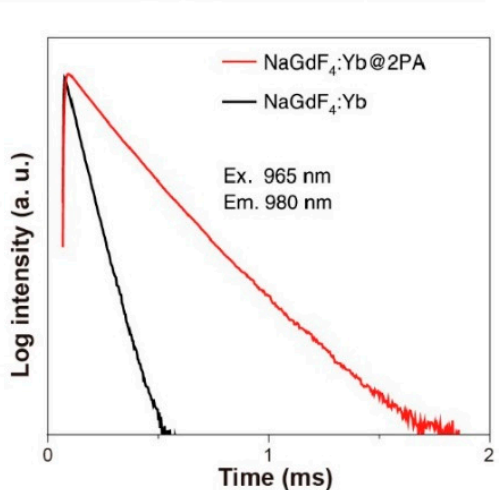

(c)
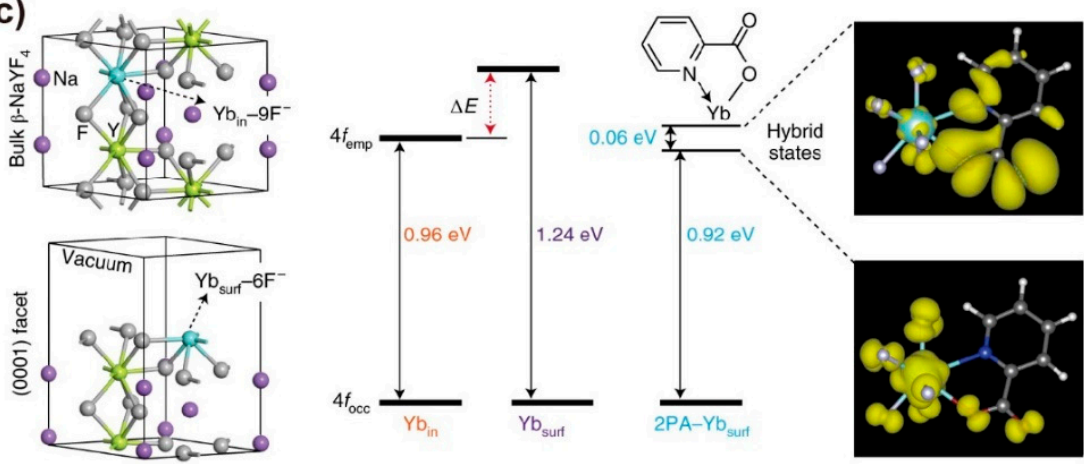

Figure 5. (a) Schematic diagram of the lifetime changing due to the existence of FRET process from UCNPs to dye molecules. Reproduced with permission from [54]. Copyright 2017, American Chemical Society. (b) Schematic representation of the structure of the $\mathrm{NaYF}_{4}$ : Tm@PC-IR-820 nanocomposites, the absorbance and emission in the same transition $\left({ }^{3} \mathrm{H}_{6}{ }^{3} \mathrm{H}_{4}\right)$ of $\mathrm{NaYF}_{4}$ : Tm nanoparticles and the variation of lifetime affected by the amount of IR- 820 dye molecules. Reproduced with permission from [55]. Copyright 2019, WILEY-VCH. (c) The optimized structure shows ytterbium atoms located in the interior $\left(\mathrm{Yb}_{\text {in }}\right)$ and exterior $\left(\mathrm{Yb}_{\text {surf }}\right)$ position, the simulated $4 \mathrm{f}$ energy levels of ytterbium atoms, the spatial distribution of the charge densities for coupling states and the lifetime decay curves of $\mathrm{Yb}^{3+}$ at $980 \mathrm{~nm}$ with and without $2 \mathrm{PA}$ capping on the $\mathrm{NaGdF}_{4}: 5 \% \mathrm{Yb}$ nanoparticles $(10 \mathrm{~nm})$ excited at $965 \mathrm{~nm}$. Reproduced with permission from [59]. Copyright 2021, Nature Publishing Group.

\subsection{Changing Temperature}

The synthesized process would affect the crystallinity, phase state and volume of nanoparticles and thus influence the decay behaviors. Vatsa et al. studied the decay process of $\mathrm{GdVO}_{4}$ : $\mathrm{Dy}^{3+}$ nanoparticles after heat treatment. When heated from $500{ }^{\circ} \mathrm{C}$ to $900{ }^{\circ} \mathrm{C}$, the lifetime of $\mathrm{Dy}^{3+}\left({ }^{4} \mathrm{~F}_{9 / 2}\right.$ level) extended from $114 \mu$ s to $260 \mu$ s due to the reduction of the non-radiative process by surface inhomogeneities. This increase in lifetime can also be ascribed to the decrease in the surface defects with the particle size increases in the heat treatment process (Figure 6a) [60]. For $\mathrm{YVO}_{4}: \mathrm{Ln}^{3+}\left(\mathrm{Ln}^{3+}=\mathrm{Dy}^{3+}, \mathrm{Eu}^{3+}\right)$ nanoparticles, the increase in covalent bond interaction caused by heat treatment led to a red shift in $\mathrm{V}-\mathrm{O}$ charge transfer (CT). Similarly, the lifetimes of $\mathrm{Dy}^{3+}$ at ${ }^{4} \mathrm{~F}_{9 / 2}$ and $\mathrm{Eu}^{3+}$ at ${ }^{5} \mathrm{D}_{0}$ increase with temperature from $500{ }^{\circ} \mathrm{C}$ to $900{ }^{\circ} \mathrm{C}$ due to the reduction of the non-radiative process on the surface of the particles [61].

As is well known, the decay time constant is inversely proportional to the radiative and non-radiative transition rates in the cross-relaxation process. The luminescence lifetime decreases with the increase of ambient temperature in most cases. The decay time with specific emissions produced by radiative transition rarely varies with temperature, while the non-radiative decay rate changes significantly with temperature [62]. For example, the lifetime of $\mathrm{Yb}^{3+}$ at $1000 \mathrm{~nm}$ reduced from $470 \pm 11 \mu$ s to $390 \pm 12 \mu \mathrm{s}$ in $\mathrm{NaYF}_{4}: \mathrm{Nd}^{3+}$, $\mathrm{Yb}^{3+}$ nanoparticles as the temperature rose from $25^{\circ} \mathrm{C}$ to $45^{\circ} \mathrm{C}$. While the thermal coefficient $\alpha_{\tau}$ calculated by the TGI system was almost unchanged $\left(-0.0092 \sim-0.010^{\circ} \mathrm{C}^{-1}\right)$ 
(Figure 6b,e) [63]. Moreover, cross-relaxation between $\operatorname{Tm}^{3+}\left({ }^{1} \mathrm{G}_{4}\right)$ usually occurs when raising the emitter concentration or temperature. Yu et al. compared the sensitivity of $\beta$ $\mathrm{PbF}_{2}: \mathrm{Tm}^{3+} / \mathrm{Yb}^{3+}$ with different $\mathrm{Tm}^{3+}$ doping concentrations. They found that the relative sensitivity maximum values of ${ }^{1} \mathrm{G}_{4}$ state lifetime in $0.0005 \mathrm{Tm}, 0.01 \mathrm{Tm}$ and $0.05 \mathrm{Tm}$ nanoparticles are $0.16 \% \mathrm{~K}^{-1}, 0.26 \% \mathrm{~K}^{-1}$ and $0.46 \% \mathrm{~K}^{-1}$ at $488 \mathrm{~K}$, respectively, indicating the potential ability as an indicator of upconversion luminescence lifetime-based thermometer [64].

In addition, the host matrix has a significant effect on thermal sensitivity. Díaz et al. found that oxide materials are more sensitive than fluoride ones by comparing the decay curves of $\mathrm{NaYF}_{4}: \mathrm{Er}, \mathrm{Yb}$ and $\mathrm{NaY}_{2} \mathrm{~F}_{5} \mathrm{O}: \mathrm{Er}, \mathrm{Yb}$ nanoparticles at room temperature and $60{ }^{\circ} \mathrm{C}$. [65]. The temperature dependency of $\mathrm{Yb}^{3+}$ emission lifetime in $\mathrm{NaYF}_{4} @ \mathrm{NaYF}_{4}: \mathrm{Yb}^{3+}$, $\mathrm{Nd}^{3+} @ \mathrm{CaF}_{2}$ nanoparticles was determined by the energy transfer and back energy transfer rate, the energy migration process (among $\mathrm{Yb}^{3+}$ ), as well as radiative and non-radiative transition. Both the concentration of $\mathrm{Nd}^{3+}$ and $\mathrm{Yb}^{3+}$ affected the temperature sensitivity by changing the distance of $\mathrm{Yb}^{3+}-\mathrm{Yb}^{3+}$ and $\mathrm{Yb}^{3+}-\mathrm{Nd}^{3+}$, which in turn affected the back energy transfer processes from $\mathrm{Yb}^{3+}$ to $\mathrm{Nd}^{3+}$ and energy migration between $\mathrm{Yb}^{3+}$ ions. $\mathrm{NaYF}_{4} @ \mathrm{NaYF}_{4}: 20 \% \mathrm{Yb}^{3+}, 60 \% \mathrm{Nd}^{3+} @ \mathrm{CaF}_{2}$ as the nanoprobe possessed optimum thermal sensitivity through varying doping concentrations of $\mathrm{Yb}^{3+}$ and $\mathrm{Nd}^{3+}$, in which the lifetime of $\mathrm{Yb}^{3+}$ at $980 \mathrm{~nm}$ descended from $898 \mu$ s to $450 \mu$ s when the temperature increased from $10{ }^{\circ} \mathrm{C}$ to $64{ }^{\circ} \mathrm{C}$. (Figure $\left.6 \mathrm{c}, \mathrm{f}\right)[66]$.

Interestingly, $\mathrm{Li}$ et al. demonstrate the lifetime compensation with temperature in $\mathrm{NaErF}_{4} @ \mathrm{NaGdF}_{4}$ core-shell nanoparticles. The temperature-independent lifetime is attributed to the balance between lattice expansion (prolonging the lifetime) and thermal quenching (shortening the lifetime). A considerable energy migration process occurs in the high-doping concentration of $\mathrm{Er}^{3+}$, and the efficiency is proportional inversely to the average donor-acceptor distance with sixth order of magnitude. As a consequence, elevated temperature induces the lattice to expand, leading to a longer transfer distance, and ultimately prolonging the lifetime of $\mathrm{Er}^{3+}$. However, the prolonged lifetime caused by lattice expansion compensated for the difference value of the shorter lifetime aroused by thermal quenching, resulting in the temperature-independent lifetime (Figure 6d) [67].
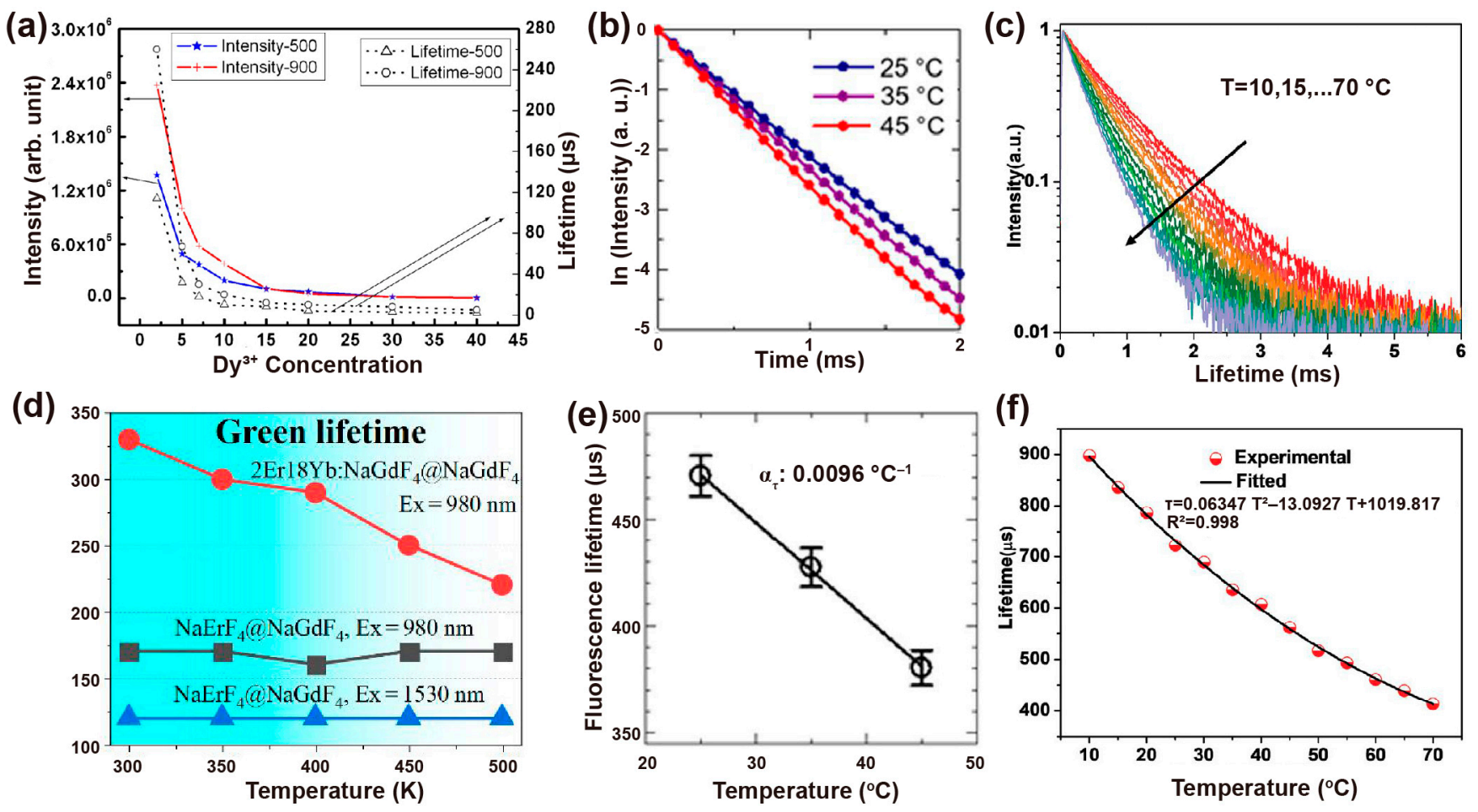

Figure 6. (a) Intensity (left) and the corresponding decay lifetime of $\mathrm{Dy}^{3+}$ at ${ }^{4} \mathrm{~F}_{9 / 2}$ states (right) with the dependent variable of $\mathrm{Dy}^{3+}$ concentration when excited at $310 \mathrm{~nm}$. Reproduced with permission 
from [60]. Copyright 2009, AIP Publishing. (b) Luminescence decay curves of $\mathrm{NaYF}_{4}: \mathrm{Nd}^{3+}, \mathrm{Yb}^{3+}$ at different experimental temperatures and (e) the corresponding calibration curve of temperature vs. luminescence lifetime. Reproduced with permission from [63]. Copyright 2019, Nature Publishing Group. (c) The decay curves of the measured $\mathrm{NaYF}_{4} @ \mathrm{NaYF}_{4}: 20 \% \mathrm{Yb}^{3+}, 60 \% \mathrm{Nd}^{3+} @ \mathrm{CaF}_{2}$ nanoprobe at various temperatures and (f) corresponding nonlinear fitted curves between measured lifetime and temperature ranging from $10{ }^{\circ} \mathrm{C}$ to $70{ }^{\circ} \mathrm{C}$. Reproduced with permission from [66]. Copyright 2020, WILEY-VCH. (d) Negative correlation curves of the lifetime of $\mathrm{Er}^{3+}$ at ${ }^{4} \mathrm{~S}_{3 / 2}$ versus ambient temperature for $\mathrm{NaErF}_{4} @ \mathrm{NaGdF}_{4}$ and $\mathrm{NaErF}_{4}: 18 \% \mathrm{Yb}, 2 \% \mathrm{Er} @ \mathrm{NaGdF}_{4}$ nanoparticles. Reproduced with permission from [67]. Copyright 2020, MDPI.

\section{Bioapplications}

With proper surface functionalization, lanthanide-doped nanoparticles possessed good biocompatibility and low toxicity [68]. Additionally, the pulsed laser illumination has a lower thermal effect than continuous-wave laser emission, which was harmful in biological applications [23]. Therefore, lanthanide-doped nanoprobes combined with lifetime sensing technology involving time-gated and lifetime coded imaging is widely used in biology and medicine [18]. This review gives a perspective of lifetime-based sensing and imaging in biological applications at molecule, cell, organ and living body levels.

\subsection{Ions and Molecules Detection}

The quantitative detection of targets based on intensity was unreliable due to the inhomogeneous scattering and absorption. Utilizing the lifetime variation of donor and acceptor, lifetime sensing based on the FRET mechanism could monitor ions' concentration accurately. Zhang et al. integrated the $\mathrm{Nd}^{3+}$-doped nanoparticle (energy donor) and MY1057 (energy acceptor) to detect peroxynitrite $\left(\mathrm{ONOO}^{-}\right)$in the tumor-microenvironment based on the lifetime of NIR-II emission. The luminescence lifetime of the nanosensor at $1060 \mathrm{~nm}$ shortened with the increase in the amount of the surface dye molecules. The energy acceptor MY-1057 was destructed after reacting with reactive nitrogen species (especially $\mathrm{ONOO}^{-}$), resulting in the lifetime being recovered. Furthermore, the lifetime of the nanosensor would recover from $202 \mu$ s to $303 \mu$ s continuously after $\mathrm{ONOO}^{-}$addition, showing linearity corresponding to $\mathrm{ONOO}^{-}$concentration while independent of the penetration depth $(0,2,5 \mathrm{~mm})$. As a result, the $\mathrm{ONOO}^{-}$concentration could be measured under unknown tissue penetration depth on a basis of standard curve due to the reliable lifetime-based $\mathrm{ONOO}^{-}$detection (Figure 7a) [69]. Besides, Li et al. synthesized a lifetime-responsive nanocomposite consisting of $\mathrm{NaYF}_{4}$ : Tm nanoparticles and IR-820 dye molecules. The energy transfer from $\mathrm{Tm}^{3+}$-doped nanocrystal to IR- 820 provided a tunable luminescence lifetime. $\mathrm{ClO}^{-}$can destruct the dye and recover the lifetime of $\mathrm{Tm}^{3+}$. Based on lifetime changes, the concentration of $\mathrm{ClO}^{-}$could be detected (Figure 7c) [55].

Time-resolved fluorescence microscopy could monitor target fluorescence by distinguishing the differences of fluorescence lifetimes in the nanosecond regime. For metal ions, Zhang et al. utilized the time-resolved fluorescence signals of $\mathrm{BSA} / \mathrm{Tb}^{3+}$ to detect metal ions, involving $\mathrm{Cu}^{2+}, \mathrm{Co}^{2+}, \mathrm{Zn}^{2+}, \mathrm{Mn}^{2+}, \mathrm{Ni}^{2+}, \mathrm{Pb}^{2+}, \mathrm{Ag}^{+}, \mathrm{Li}^{+}, \mathrm{Na}^{+}, \mathrm{Fe}^{3+}, \mathrm{Ca}^{2+}, \mathrm{Mg}^{2+}$, $\mathrm{Al}^{3+}, \mathrm{K}^{+}, \mathrm{Cd}^{2+}, \mathrm{Cr}^{3+}$ and $\mathrm{Hg}^{2+}$ in two $\mathrm{pH}$ buffers (7.4 and 8.5). A $2000 \mu$ sate time and a $50 \mu$ s delay time were settled for time-resolved fluorescence spectra by recording at $548 \mathrm{~nm}$. Furthermore, the sensing platform could distinguish the various concentrations of the identical metal ions and the variety of metal ions mixture, even in biofluids [70]. Nagano et al. designed luminescent $\mathrm{Eu}^{3+}$ complexes (Eu-7) for time-resolved, long-lived luminescence microscopy (TRLLM). With Eu-7 injecting into a single Hela cell, the lifetime window centered at $617 \pm 37 \mathrm{~nm}$ of $\mathrm{Eu}^{3+}$-based luminescence was collected under $360 \pm 40 \mathrm{~nm}$ excitation. An increased luminescence enhancement was observed when the intracellular $\mathrm{Zn}^{2+}$ mixed with pyrithione, and decreased with the addition of cell-membrane-permeable chelator TPEN (N,N, $\mathrm{N}^{\prime}, \mathrm{N}^{\prime}$-tetrakis(2-picolyl)ethylenediamine). As the delay times prior to counting and gate time were 70 and $808 \mu \mathrm{s}$, respectively, the intracellular $\mathrm{Zn}^{2+}$ con- 
centration variation in living cells could be examined by using the TRLLM system with $\mathrm{Zn}^{2+}$-sensitive luminescent lanthanide probe [Eu-7] (Figure 7b) [71].

$\mathrm{Li}$ et al. designed a water-soluble nanocomposite $\mathrm{NaYF}_{4}: 5 \% \mathrm{Nd}$ and dye Cy860 enveloped by phosphatidylcholine (NPs@dye@PC). The Cy860 dye can quench the luminescence of lanthanide-doped nanoparticles. After hypochlorous acid (HCIO) reacted with organic dye molecules, the quenching process was broken, and the luminescence of lanthanide-doped nanoparticles was recovered. Meanwhile, the lifetime of $\mathrm{Nd}^{3+}$ at $893 \mathrm{~nm}$ was shortened from $51 \mu$ s to $16 \mu$ s due to the FRET and inner filter effect. Utilizing the time-gated technique and signal collection method, they used $\mathrm{NaYF}_{4}: \mathrm{Nd} @ \mathrm{Cy} 860 @ \mathrm{PC}$ nanoprobe to detect the concentration of $\mathrm{HCIO}$ in a living mouse model. Of note, the average relative deviations of $\mathrm{HCIO}$ concentration were only $0.61 \%$ and $1.74 \%$ via ratiometric detection, while the tissue depth increased up to $2 \mathrm{~mm}$ and $3 \mathrm{~mm}$, respectively (Figure 7d) [72]. Yuan et al. designed and synthesized a time-gated luminescence TGL probe (TR-HCIO) for specific detection of $\mathrm{HCIO}$, in which luminescent $\mathrm{Tb}^{3+}$ (energy donor) nanoparticles were conjugated with a rhodamine derivative (energy acceptor). After reacting with $\mathrm{HCIO}$, the rhodamine emission at $580 \mathrm{~nm}$ increased while the $\mathrm{Tb}^{3+}$ emission at $540 \mathrm{~nm}$ decreased, resulting in an increase in the TGL intensity proportion of rhodamine to $\mathrm{Tb}^{3+}\left(\mathrm{I}_{560} / \mathrm{I}_{540}\right)$ up to $\sim 9$-fold. The luminescence lifetime of $\mathrm{Tb}^{3+}$ decreased from $588 \mu \mathrm{s}$ to $254 \mu$ s due to the FRET process and has excellent linearity of the variation of HCIO concentration from $0.5 \mu \mathrm{M}$ to $30 \mu \mathrm{M}(\mathrm{r}=0.99)$. With dual signal outputting by ratiometric TGL and luminescence lifetime, TR- HCIO was applied to determine HCIO in HepG2 cells [73].

(a)

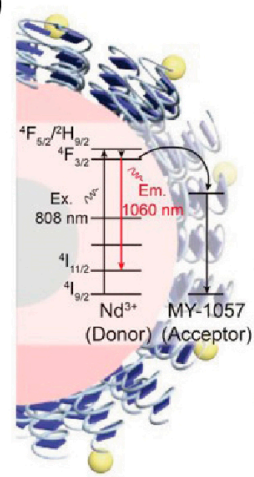

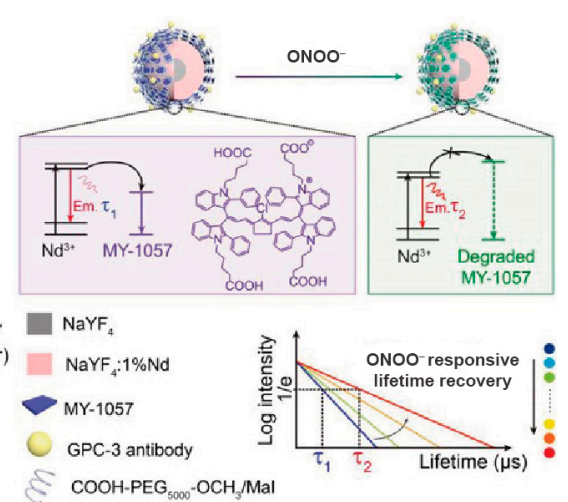

$\mathrm{COOH}-\mathrm{PEG}_{5000}-\mathrm{OCH}_{3} / \mathrm{Mal}$ (b)

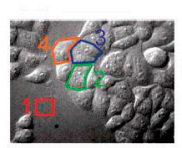

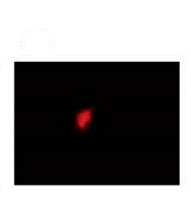
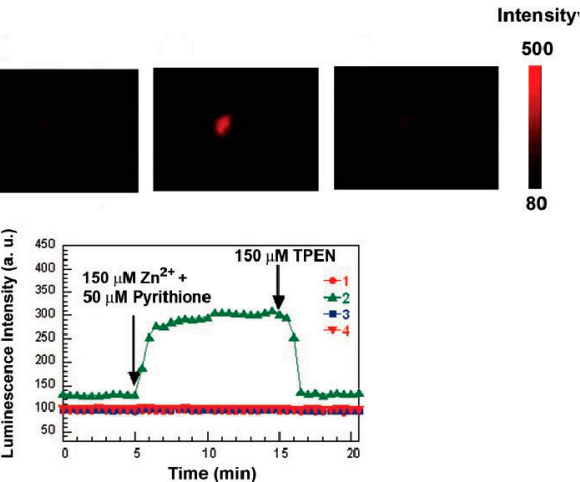

Concentration of $\mathrm{NaClO}$ (c)
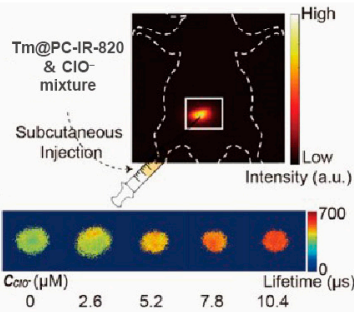

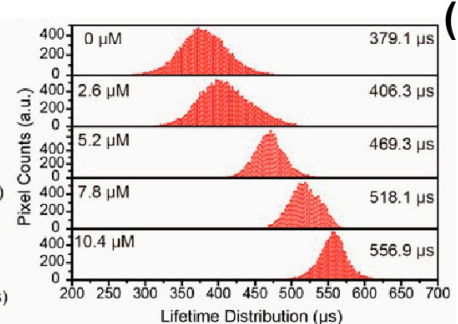

(d)

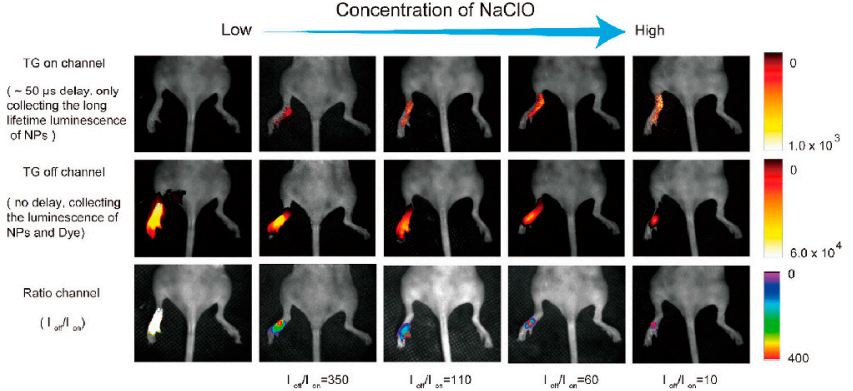

Figure 7. (a) Schematic diagram of nanosensor DSNP@MY-1057-GPC responding to ONOO- ${ }^{-}$Reproduced with permission from [69]. Copyright 2020, WILEY-VCH. (b) Time-resolved luminescence imaging of $\mathrm{Zn}^{2+}$ in living HeLa cells. Reproduced with permission from [71]. Copyright 2007, American Chemical Society. (c) Simulated luminescence lifetime imaging of the detection of responsive $\mathrm{ClO}^{-}$. Reproduced with permission from [55]. Copyright 2019, WILEY-VCH. (d) The images of living mice in vivo with injection of $25 \mu \mathrm{L}$ sodium hypochlorite solution and $25 \mu \mathrm{L} \mathrm{NaYF} 4$ : Nd@Cy860@PC aqueous solution (3 mol/L). Reproduced with permission from [72]. Copyright 2019, American Chemical Society.

Vitamin $C$ distribution and dynamic activities could be monitored by the time-gated luminescence microscopy. Yuan et al. developed a probe responding to ascorbic acid 
(vitamin C) conjugating two nitroxide radicals and a luminescent europium complex. The nitroxide radicals prevented the probes from emitting luminescence until vitamin $C$ was added to form a hydroxylamine derivative. The probes responded to vitamin $\mathrm{C}$ concentration linearly with a limit of detection (LOD) of $9.1 \mathrm{nM}$, which is lower than electrochemical methods by two orders of magnitude. The method of time-gated luminescence microscopy enabled real-time and specific monitoring of the cellular uptake, endogenous production and mapping of vitamin C in living Daphnia magna with free background [74].

\subsection{DNA Detection}

The pathogen DNA strands could be detected by using lifetime coding and decoding with downconversion lanthanide luminescence in microspheres. Jin et al. encapsulated a trivalent europium complex of thenoyltrifluoroacetonate Eu (donor) and a hexafluorophosphate salt of cationic coumarin 50 (acceptor dyes) into porous polystyrene beads by solvent swelling. The average donor-to-acceptor distance could be manipulated by stepwise varying their concentrations, achieving the fine-tuned lifetimes of the microspheres. They carried out a biological experiment for high-throughput simultaneous detection of different pathogen DNAs (single strands), including human immunodeficiency virus, Ebola virus, hepatitis B virus and human papillomavirus (HPV) 16. The pathogen DNAs were added into the test panel composed of five types of conjugated microspheres encoded with different life spans, and Qdot 565 was added as a reporter dye. With the time-resolved orthogonal scanning automated microscopy analysis, the lifetime of $\mathrm{Eu}^{3+}$ complex in lanthanide-encoded microspheres were recovered by detecting the time-gated luminescence, which can identify their types of pathogen DNAs by decoding the lifetimes (Figure 8a) [75].

Similarly, Zhang et al. synthesized a series of nanoparticles with a settled lifetime by regulating the doped proportion of activators and the thickness of the energy migration layer. These nanoparticles were loaded into microspheres and modified by the DNA probe with nine high-risk HPV subtypes. With fluorescence dye 6-carboxyfluorescein as the reporter for DNA detection, the nanoparticles modified with DNA probe were added into a solution including PCR amplified DNAs of HPV targets. The HPV positive sample both of HPV 16 and HPV 18 could be distinguished by using the time-resolved imaging scanning system (Figure 8b) [42].

(a)

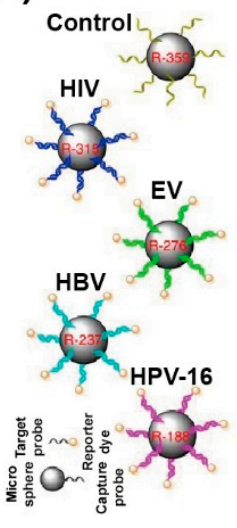

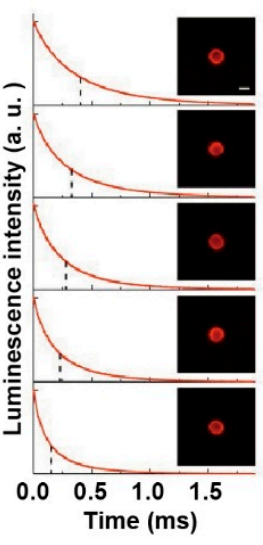

(b)

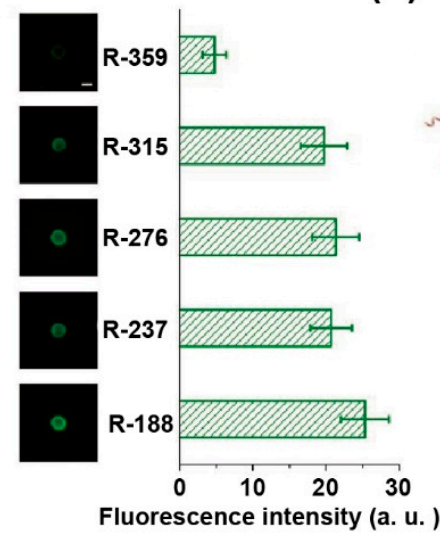

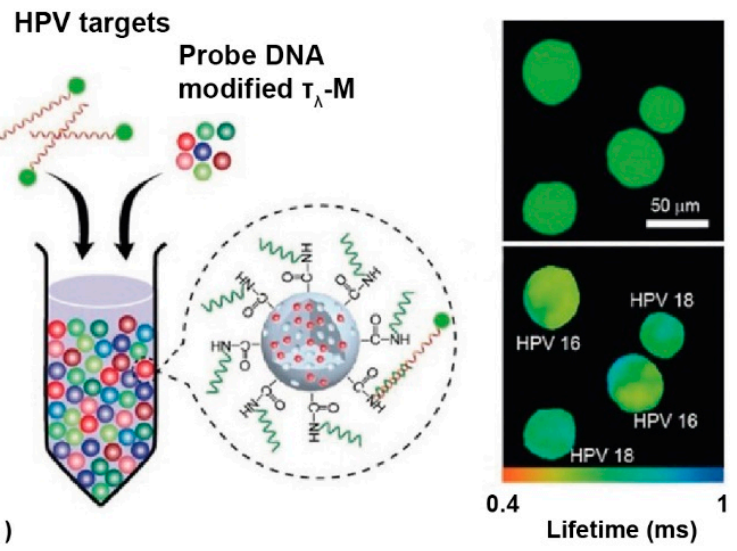

Figure 8. (a) Diagram of the five types of Eu-LRET microspheres conjugated to five different DNA sequences, in which the microspheres and amounts of pathogen DNAs were confirmed by the luminescence decay curves of $\mathrm{Eu}^{3+}$ and reporter fluorescence intensities, respectively. Reproduced with permission from [75]. Copyright 2014, Nature Publishing Group. (b) Schematic diagram of $\tau_{\lambda}$-M for detecting HPV subtypes, and the confocal images with the corresponding lifetime images after incubating complementary target DNAs, respectively. Reproduced with permission from [42]. Copyright 2018, WILEY-VCH. 


\subsection{Protein Detection}

A strategy to detect protease is to utilize lanthanide nanoprobes, which exhibit the long lifetimes and strong luminescence in the presence of an amino group, and a reverse trend with the protection of acyl groups. Kikuchi et al. synthesized lanthanide-based antennachelator conjugates with aniline derivative groups as the antennas. This conjugation has strong luminescence and a long lifetime $(1.5 \mathrm{~ms})$ at $350 \mathrm{~nm}$ when calpain I and leucine aminopeptidase (LAP) are added. These probes could exclude background fluorescence signals, suitable for detecting protease activities such as LAP and calpain I by time-resolved assays [76].

Similarly, Kikuchi et al. prepared a luminescent lanthanide probe TPA-Eu using timeresolved luminescence microscopy for protein imaging. The lifetime was $1.25 \mathrm{~ms}$ at $616 \mathrm{~nm}$, which could be applied to detect TPA-Eu labeled on cell-surface proteins. The long lifetime could effectively separate the live-cell imaging from background signals (Figure 9a) [77]. Vuojola et al. constructed a hybrid FRET system consisting of $\mathrm{Tb}^{3+}$ with lanthanide-binding peptide (LBP) and green fluorescent protein (GFP). LBP can prolong the emission lifetime and can be applied in time-gated detection. After LBP and GFP were digested by enzyme, the long-lived sensitized acceptors were removed. The variation of the time-gated signals of terbium at $545 \mathrm{~nm}$ and the sensitized acceptor emission at $520 \mathrm{~nm}$ were monitored and used to detect the presence of caspase-3 inhibitor Z-DEVD-FMK [78].

The time-resolved detection could trace the biomolecules such as avidin with FRET biosensor, which can eliminate the background signals and improve the sensitivity. Chen et al. designed a hybrid system; $\mathrm{NaYF}_{4}: \mathrm{Ce} / \mathrm{Tb}$ nanocrystals could transfer the energy to fluorescein isothiocyanate (FITC). The lifetime of $\mathrm{Tb}^{3+}$ at ${ }^{5} \mathrm{D}_{4}$ decreased with the concentration of avidin improving from 0 to $500 \mathrm{nM}$. Using the model system, they could achieve an LOD of $5 \mathrm{nM}$ (Figure 9b) [79]. By utilizing time-resolved fluorescence resonance energy transfer (TR-FRET), the avidin could be detected with the detection limit of $3.0 \mathrm{nM}$ by using $\mathrm{ZrO}_{2} \mathrm{NP}$ bioprobes [80]. In addition, Chen et al. synthesized $\mathrm{CaF}_{2}: \mathrm{Ln}^{3+}(\mathrm{Ln}=\mathrm{Ce}, \mathrm{Tb}$; $\mathrm{Yb}, \mathrm{Er} ; \mathrm{Yb}, \mathrm{Tm}) \mathrm{NPs}$ with a size of sub-10 nm, which could sensitively detect avidin in homogeneous TR-FRET bioassays. Due to great spectral overlap, amino terminal fragment (ATF) coupled with $\mathrm{CaF}_{2}$ : Ce, Tb NP (emitting at $491 \mathrm{~nm}$ ) labeled FITC (emitting at $490 \mathrm{~nm}$ ) for TR-FRET detection. Therefore, the excitation energy of $\mathrm{CaF}_{2}: \mathrm{Ln}^{3+}$ could be transferred to nearby FITC on account of the specific bond between avidin and biotin. The TR-FRET signal was enhanced gradually at the expense of the $\mathrm{Tb}^{3+}$ signal as the amount of avidin increased. The calibration curve for avidin concentrations from $0.1 \mathrm{nM}$ to $430 \mathrm{nM}$ exhibits that the signal of FITC/Tb in TR-FRET increases with the avidin concentration. The LOD is approximately $164 \mathrm{pM}$, which is the lowest detection limit for bioprobes on the basis of $\mathrm{Ln}^{3+}$-doped inorganic nanoparticles. Specially, they designed a system to detect soluble urokinase plasminogen activator receptor with ATF-coupled nanoparticles as the probes, whose LOD of tumor marker suPAR is $328 \mathrm{pM}$ [81].

On the basis of the FRET mechanism, lanthanide nanoparticles can provide sensitive detection by using their decay time signals. Zhang et al. designed a hybrid system of UCNPaptamer/ssDNA-pyropheophorbide-a (PPA)-doxorubicin (DOX) [UAS-PD] with $540 \mathrm{~nm}$ and $655 \mathrm{~nm}$ emission for targeted cancer therapy. The Black Hole Quencher-1 (BHQ-1) bore on ssDNA without the target cell. It could quench the luminescence of UCNPs at $540 \mathrm{~nm}$ due to FRET, but had a limited effect on $655 \mathrm{~nm}$ emission. A spontaneous conformational reorganization would occur when approaching specific cancer cells, moving ssDNA away from UCNPs and making PPA close to UCNPs. PPA decreased the luminescence intensity at $655 \mathrm{~nm}$ and recovered $540 \mathrm{~nm}$ emission due to FRET. Meanwhile, it affected the lifetime of both $540 \mathrm{~nm}$ and $655 \mathrm{~nm}$. As a result, an extracellular cancer-specific biomarker PTK7 was developed to activate the UAS-PD as a probe. The lifetime of UAS-PD at $540 \mathrm{~nm}$ and $655 \mathrm{~nm}$ was measured to be $339.22 \mu \mathrm{s}$ and $668.61 \mu \mathrm{s}$, respectively. Nevertheless, in the presence of PKT7, the lifetime of hybrid system increased by $476.33 \mu$ s at $540 \mathrm{~nm}$, while the decay times at $655 \mathrm{~nm}$ decreased to $404.52 \mu$ s due to FRET from UAS-PD to BHQ-1 and 
PPA. Specially, the ratiometric lifetime signal provided an extremely low LOD of $3.9 \mathrm{nM}$ for PTK7 [82].

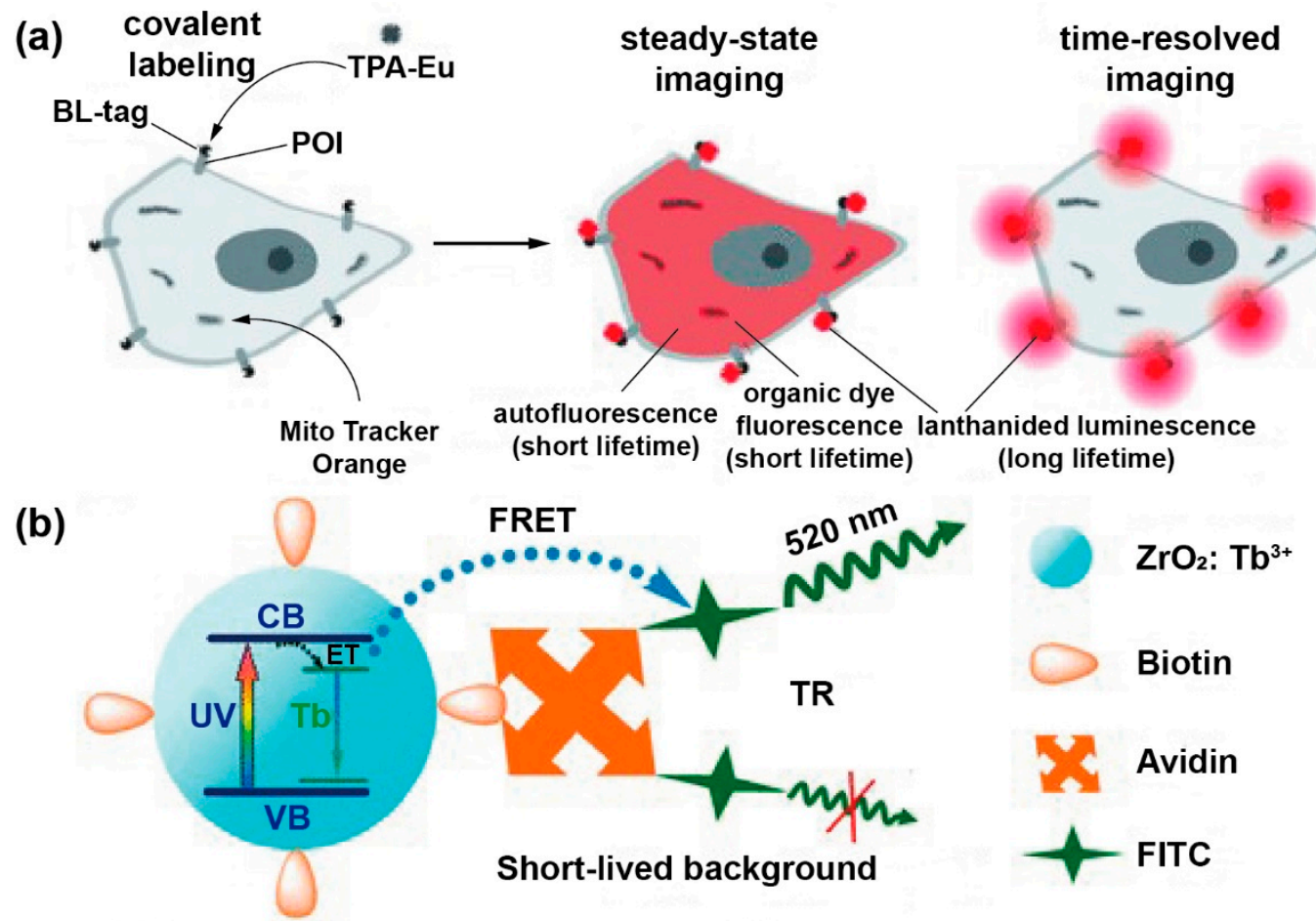

Figure 9. (a) Schematic representation of mutant $\beta$-lactamase-based protein labeling system, in which the luminescent lanthanide probe (TPA-Eu) was used for imaging cell-surface proteins (POIs). Reproduced with permission from [77]. Copyright 2011, WILEY-VCH. (b) Schematic diagram of TRFRET detecting of avidin by employing biotinylated NCs (donor) and FITC (acceptor). Reproduced with permission from [79]. Copyright 2011, WILEY-VCH.

The sensitivity of immunoassays could be improved by using lanthanide-labeled nanoparticles with time-resolved immunofluorometric assays (TrIFA). Li et al. coated the luminescent $\mathrm{Eu}^{3+}$ and $\mathrm{Tb}^{3+}$ chelates covalently on the surface of silica nanoparticles to conjugate the antibodies or bind antibodies. As a comparison, the lifetime was no longer than $0.3 \mathrm{~ms}$ for $\mathrm{Eu}^{3+}$-BHHCT after encapsulation in silica nanoparticles, while the lifetime of $\mathrm{Tb}^{3+}$-BPTA chelates decreased prominently from $2.68 \mathrm{~ms}$ to $1.52 \mathrm{~ms}$ after encapsulation. The as-prepared conjugates in TrIFA could detect hepatitis B e antigen ( $\mathrm{HBeAg}$ ) and hepatitis B surface antigen (HBsAg). Utilizing the conjugates, the TrIFA for HBsAg possessed a comparable or lower LOD $(0.0092 \mu \mathrm{g} / \mathrm{L})$ than ELISA while the TrIFA for HBeAg possessed a much lower LOD (10.0 National Centre Unit (NCU)/L) than ELISA. By synchronizing TrIFA, the detection limits reached $0.033 \mu \mathrm{g} / \mathrm{L}$ for HBsAg and $27.0 \mathrm{NCU} / \mathrm{L}$ for $\mathrm{HBeAg}$, which is close to those of the individual assays [83].

\subsection{Cell Labeling}

Lanthanide bioprobes with time-gated detection enable rapid identification and quantification of cells bearing low-abundance surface biomarkers. CD $34^{+}$cells are the hematopoietic stem cells, whose surface possesses the specific expression of CD34 protein. Jin et al. synthesized functionalized polystyrene nanoparticles containing europium and stained $\mathrm{CD} 4^{+}$cells with a streptavidin-europium complex conjugate. Biotinylated anti-CD34 antibodies stained $\mathrm{CD} 34^{+}$cells, and were imaged by time-gated luminescence, suppressing autofluorescence background signal (Figure 10a). As a result, the signal intensity was improved by a factor of $\sim 20$, which could quantify the surface antigens of low expression on a single cell. Furthermore, with the assistance of an orthogonal scanning automated 
microscopy, they obtained the quantitative statistical data of numerous CD4 cells on microscopy slides. They separated $98 \%$ target cell population from stained cells with a coefficient of variation of $31 \%$ [84].

Precise detection of tumor cells is critical for diagnosing early-stage cancer, forcing researchers to develop highly sensitive methods. The lifetime-resolved luminescent lanthanide technology could obtain high signal intensity by suppressing the background fluorescence. Chen et al. synthesized anti-EpCAM-antibody-modified $\mathrm{NaEuF}_{4} \mathrm{NPs}$ $\left(\mathrm{NaEuF}_{4}-\mathrm{Ab}\right)$ to detect circulating tumor cells (CTCs) in whole blood samples without CTC enrichment. This amplified the signal through enhanced dissolution of time-resolved photoluminescence and elimination of short-lived autofluorescence interference. The detection of blood breast cells had a LOD of 1 cell/well in a 96-well plate. As a result, the direct detection of blood breast cancer cells has a detection rate of $93.9 \%$ (14/15 patients) in cancer patients. The time-resolved photoluminescence could improve the signal to noise ratio of the confocal laser scanning microscope (CLSM). It amplified the signal through the enhanced dissolution of time-resolved photoluminescence and elimination of short-lived autofluorescence interference. Comparing CLSM images of EpCAM-positive MCF-7 and EpCAM-negative HeLa cells incubated with $\mathrm{NaEuF}_{4}-\mathrm{Ab}$-TRITC for $1.5 \mathrm{~h}$, the surface of MCF-7 cells emitted intense red luminescence but the surface of HeLa cells did not (Figure 10b) [85].

(a)

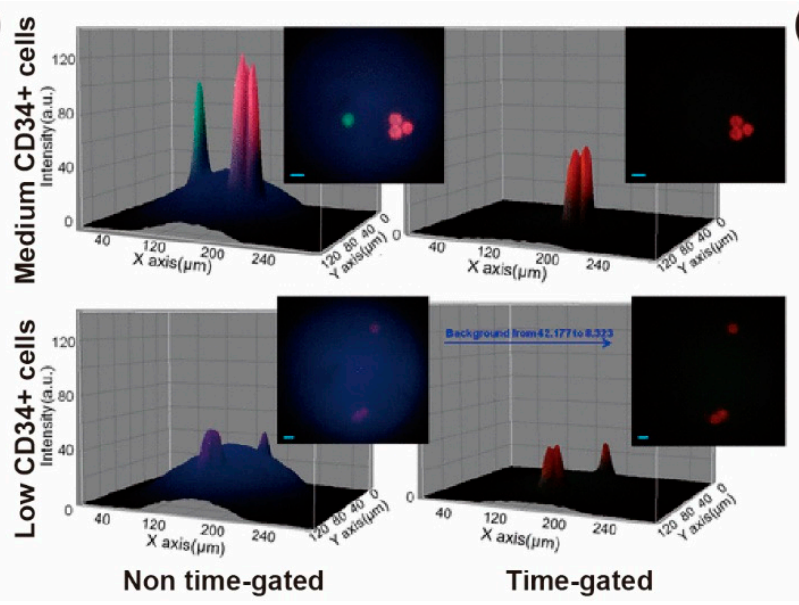

(b)

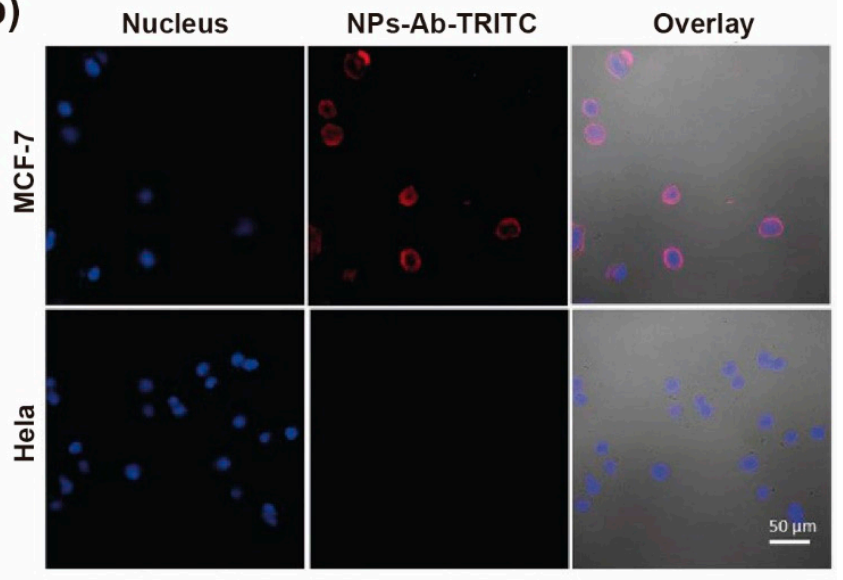

Figure 10. (a) The comparison of conventional UV fluorescence microscopy imaging (left) and timegated luminescence microscopy imaging (right) of medium. Reproduced with permission from [84]. Copyright 2012, American Chemical Society. (b) Confocal laser scanning microscopy images of EpCAM-positive MCF-7 and EpCAM-negative HeLa cells incubated with NaEuF4-Ab-TRITC for 1.5 h. Reproduced with permission from [85]. Copyright 2019, WILEY-VCH.

To increase the luminescent sensitivity, an effective strategy is to attach lanthanide chelates onto carrier molecules such as antibodies, which then were used to label surface antigens on cancer cells. Packer et al. developed a tetradentate $\beta$-diketonate-europium chelate for the immunodetection of prostate cancer cells (DU145). They conjugated MIL38 antibody to the chelate directly via lysine residues, and labeled a europium chelated secondary polyclonal antibody. As the DU145 cells (a prostate cancer cell line) were stained by conjugates, the time-gated luminescence microscopy was used to capture the images of immune-stained cancer cells while the cellular autofluorescence background was suppressed [86].

Another efficient method is to construct multiple lifetime channels, in which the lifetime could be precisely adjusted and detected. Zhang acquired a battery of Er-doped nanoparticles with settled lifetime at $1525 \mathrm{~nm}$ by control the thickness of energy relay layers and the concentration of activators. Three types of nanoparticles with settled lifetime were conjugated with primary antibodies to label the MCF-7 and BT-474 breast cancer cells, on a 
basis of detecting the biomarkers of breast cancer including progesterone receptor (PR), oestrogen receptor (ER) and human epidermal growth factor receptor-2 (HER2). Due to the different expression patterns of the three biomarkers for the two tumor subtypes, the biomarker expressions of the tumor subtypes could be quantified by analyzing the three lifetime composites according to a pattern recognition algorithm. The highest expression in the MCF-7 tumors came from ER (62.3\%), followed by PR (17.9\%) and HER2 (19.8\%). On the other hand, the BT-474 tumors expressed a large amount of HER2 (46.6\%) but moderate levels of PR $(28 \%)$ and ER $(25.4 \%)$, which were in accordance with the standard ex vivo immunohistochemistry assays [43].

\subsection{Organ Imaging}

The practical use of UCNPs is still hampered by relatively shallow penetration depth. Comfortingly, lanthanide lifetime measurements are independent of tissue thickness, which can overcome the problem by lifetime coded technology. Chen et al. coated polyacrylic acid on a series of $\mathrm{NaYF}_{4} @ \mathrm{NaYbF}_{4} @ \mathrm{NaYF}_{4}: \mathrm{Yb}^{3+} / \mathrm{Tm}^{3+} @ \mathrm{NaYF}_{4}$ via ligand exchange. They injected PAA-coated UCNPs $(100 \mu \mathrm{L}, 30 \mathrm{mg} / \mathrm{mL})$ with the lifetime of $1158 \mu \mathrm{s}$ into a Kunming mouse by tail vein injection, $20 \mu \mathrm{L}$ of PAA-coated UCNPs $(30 \mathrm{mg} / \mathrm{mL})$ with lifetimes of $1528 \mu \mathrm{s}$ and $920 \mu \mathrm{s}$ into the right and left of the abdomen through subcutaneous injection, respectively. The time-delayed images were analyzed algorithmically by MATB. By taking advantage of temporal optical multiplexed upconversion with distinct lifetimehued colors, liver and two abdomen subcutis could be seen clearly. The two close lifetimes could also be differentiated in in vivo imaging, indicating high temporal resolution abilities of the imaging system (Figure 11a,b) [41].

NIR-II luminescence has the advantage of reducing optical scattering. $\mathrm{Er}^{3+} \mathrm{emission}^{\mathrm{at}}$ $1532 \mathrm{~nm}$ combined with lifetime sensing technology attracted specific attention. The fluorescent nanoprobes with $\mathrm{Er}^{3+}$ dopant in double interfaces $\left(\mathrm{NaYF}_{4} @ \mathrm{NaErF}_{4}: \mathrm{Ce} @ \mathrm{NaYbF}_{4} @ \mathrm{NaE}-\right.$ $\mathrm{rF}_{4}$ : Ce@NaYF 4 ) was designed by Zhang et al. to generate strong luminescence intensity and regulate the lifetime distinguishably. The nanoparticles decorated with phospholipid were administrated via oral, intertumoral and intravenous injection into mouse baring with a subcutaneous tumor. Compared with other nanoparticles having larger luminescence intensity differences, these nanoprobes offered more accurate lifetime decoding for metabolically enriched organ imaging. During the $6 \mathrm{~h}$ monitoring period, it exhibited consistent characteristic lifetime compared with the agents in gut and tumor (Figure 11c) [87].

\subsection{Thermal Sensing}

Utilizing the temperature-dependent lifetime of lanthanide nanomaterials, lifetimebased thermometers have been developed to detect the temperature in the biologic microenvironment. Férid et al. synthesized $\mathrm{La}_{2} \mathrm{O}_{3}: \mathrm{Tm}, \mathrm{Er}, \mathrm{Yb}$ UCNPs and used it as luminescent thermal probes to detect the temperature in the simulative biological tissue. The employed fluorescence lifetime is from the ${ }^{1} \mathrm{G}_{4} \rightarrow{ }^{3} \mathrm{H}_{6}$ transition of $\mathrm{Tm}^{3+}$ at $480 \mathrm{~nm}$. UCNPs were placed at the same point on a biological tissue $(0.15 \mathrm{~mm}$ thickness), and then were focalized by a $1450 \mathrm{~nm}$ heating diode laser and excited by a $980 \mathrm{~nm}$ pulsed laser. The fluorescence lifetime at $480 \mathrm{~nm}$ was measured with heating laser power varying from $30 \mathrm{~mW}$ to $130 \mathrm{~mW}$. Hence, the sub-tissue temperature could be calculated by the achieved decay curves [88]. In an ex vivo experiment, a probe of water-dispersed $\mathrm{NaY}_{2} \mathrm{~F}_{5} \mathrm{O}: \mathrm{Er}, \mathrm{Yb}$ nanoparticles was injected into a chicken breast at $1 \mathrm{~mm}$ depth and heated by a laser beam. The luminescence decay curves excited by a $980 \mathrm{~nm}$ diode laser were recorded by a double beam confocal microscope. According to the calibration curves, the sub-tissue temperature could be determined by the level of a shortened lifetime [65]. 
(a)

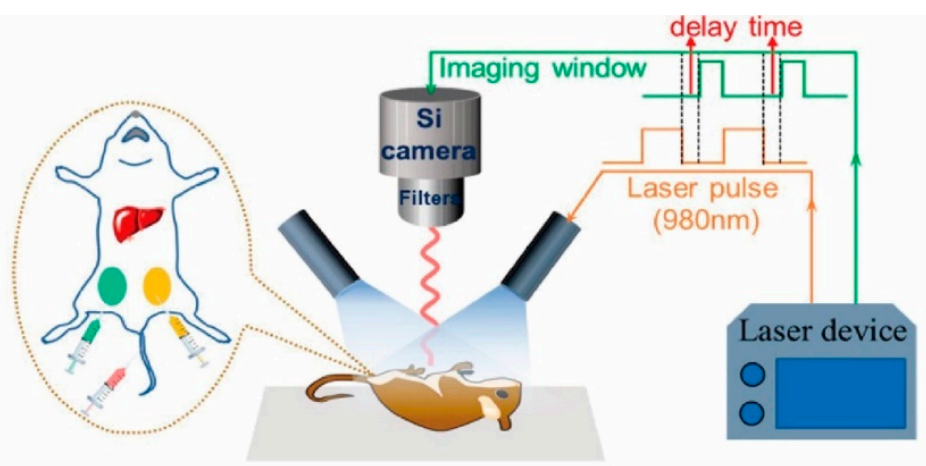

(b)

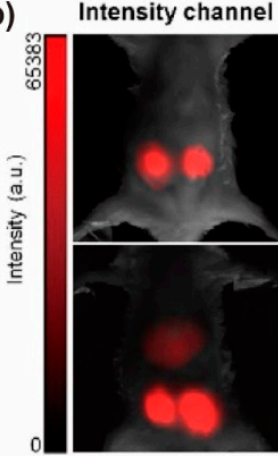

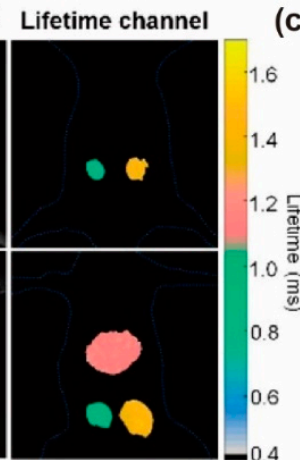

(c)
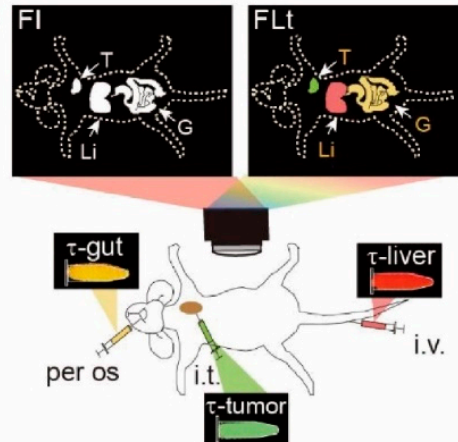

Figure 11. (a) Schematic diagram of nanoparticles with determined lifetime injecting into mouse, and then recorded by the home-built time-resolved luminescence imaging system. (b) The luminescence intensity (left) and lifetime (right) imaging of PAA-coated nanoparticles with two distinctive lifetimes injecting into a Kunming mouse and also into a second Kunming mouse (bottom). Reproduced with permission from [41]. Copyright 2020, American Chemical Society. (c) Schematic illustration of noninvasive NIR-II luminescence intensity and lifetime-based imaging for three diverse administration monitoring. Reproduced with permission from [87]. Copyright 2021, WILEY-VCH.

Integrating with QDs, the lanthanide upconversion nanomaterials exhibited excellent temperature sensing capability by utilizing arithmetic methods. Li et al. fabricated the hybrid upconversion nanoclusters (UCL-NCs) containing PbS QDs and $\mathrm{NaYbF}_{4}: 0.5 \% \mathrm{Tm} @ \mathrm{Na}-$ $\mathrm{YF}_{4}: 10 \% \mathrm{Yb} @ \mathrm{NaYF}_{4}: 50 \% \mathrm{Nd}$ (Tm-UCNPs) through an evaporation-induced self-assembly method. Both PbS QDs and Tm-UCNPs emitted around $810 \mathrm{~nm}$ through the upconversion process under $865 \mathrm{~nm}$ excitation. The lifetime of PbS QDs is responsive to the temperature at ns level, while the lifetime of Tm-UCNPs is fairly long, reaching a magnitude of $\mu \mathrm{s}$, and is independent of temperature. Pork tissue with different thicknesses mimics biological tissues to study the temperature variation of UCL-NCs. ISum was obtained by the real-time imaging, and the $I_{T m}$ was acquired by a $20 \mu$ s delayed time-resolved spectrometer. The experimental data was linearly fitted according to the ratio obtained from different thicknesses according to the formula Ratio $=\left(I_{\mathrm{Sum}}-I_{\mathrm{Tm}}\right) / I_{\mathrm{Tm}}$. Furthermore, the UCL-NCs probe could apply in vivo to monitor intratumoral temperature, and the thermal sensitivity of the hybrid system reached 5.6\%/K (Figure 12a) [89].

Dynamic temperature mapping in real-time is a powerful technology for wide-field photoluminescence lifetime imaging. Liang et al. designed a single-shot photoluminescence lifetime imaging thermometry (SPLIT), utilizing $\mathrm{NaGdF}_{4}$ : $\mathrm{Er}^{3+}, \mathrm{Yb}^{3+} @ \mathrm{NaGdF}_{4}$ nanoparticles as indicators. The lifetime of $\mathrm{Er}^{3+}$ red emission was more sensitive to temperature than the green emission, resulting from the larger energy separation between emitting and the lower-lying exciting states. Applied in longitudinal temperature monitoring successfully by overlaying chicken breast tissue, the SPLIT proved to be independent with tissue thickness and excitation light power density. When applied in a single-layer onion epidermis sample for single-cell temperature mapping, the lifetime/temperature maps were recorded in $3 \mathrm{~s}$ 
measurement window (Figure 12b). The SPLIT was demonstrated to be resilient to spatial intensity variation, while being advantageous in handling temporal intensity variation [90].

The luminescence lifetime imaging in the NIR could be used for temperature sensing. In the experiment of Soga, the temperature was found to be independent with meat depth from $0 \mathrm{~mm}$ to $1.4 \mathrm{~mm}$ and luminescence intensity [63]. Li et al. designed a $\mathrm{Nd}-\mathrm{Yb}$ co-doped nanothermometer to detect the temperature in vivo. The $\mathrm{Nd}^{3+}$ ions possess thermally rich energy levels to assemble responsive energy for the endogenous relative thermal response. In this structure, $\mathrm{Yb}^{3+}$ as energy acceptor was packed closely with $\mathrm{Nd}^{3+}$ in a nanocrystal with a diameter of $11 \mathrm{~nm}$, owning tunable intensity and lifetime. The various lifetimes of $\mathrm{Yb}^{3+}(975 \mathrm{~nm})$ corresponding to different temperatures could be observed due to energy transfer from ${ }^{4} \mathrm{~F}_{5 / 2}$ states of $\mathrm{Nd}^{3+}$ to $\mathrm{Yb}^{3+}$ under $793 \mathrm{~nm}$ excitation. The long circulation PEG modified nanoparticle was injected into a living mouse. After its footpad was stuck on a heat/cool pad through $793 \mathrm{~nm}$ excitation, the temperature difference could be distinguished between artery and vein, resulting from thermal relaxation. After stopping the heating process, the value of temperature loss was $10 \%$ in artery, and $25 \%$ in vein after $20 \mathrm{~min}$. The lifetime of the optimized probe exhibited an excellent temperature sensitivity of $0.27 \mathrm{~K}$ in vivo [91].

Another nanothermometer was designed for sensing temperature utilizing the NIR-II luminescence lifetime of $\mathrm{Yb}^{3+}$ at $1000 \mathrm{~nm}$, which is sensitive to temperature at different tissue depths. The $\mathrm{NaYF}_{4} @ \mathrm{NaYF}_{4}: \mathrm{Yb}^{3+}, \mathrm{Nd}^{3+} @ \mathrm{CaF}_{2}$ with a size of $13.5 \mathrm{~nm}$ acted as a probe for detecting temperature in vivo. Due to back energy transfer from $\mathrm{Yb}^{3+}$ to $\mathrm{Nd}^{3+}$ and energy migration among $\mathrm{Yb}^{3+}$ ions, the doping concentration of $\mathrm{Nd}^{3+}$ and $\mathrm{Yb}^{3+}$ could affect the temperature sensitivity. NIR-II lifetime-encoded images are acquired by a NIRsensitive InGaAs camera due to the precisely defined delay time set by the square-wave pulsed excitation laser. The luminescence lifetime versus temperature was calibrated by measuring a series of lifetime-hued images of nanoprobe solution. When the nanoprobes were injected into the inflamed and normal mouse, it exhibited a temperature difference of $2.3^{\circ} \mathrm{C}$ according to a thermal camera. In addition, it showed a high-temperature sensitivity of $1.4-1.1 \%{ }^{\circ} \mathrm{C}^{-1}$ with the biological tissue up to $4 \mathrm{~mm}$, ranging from $10{ }^{\circ} \mathrm{C}$ to $64{ }^{\circ} \mathrm{C}$. The nanothermometers could diagnose murine inflammation in vivo based on lifetime responsiveness to temperature, and map the temperature distribution in the nanoparticleprobed area (Figure 12c) [66].

\section{7. $p H$ Sensing}

It is well known that the pH-responsive fluorescein attached to UCNPs could detect $\mathrm{pH}$ by the ratiometric responses of emission intensity. Recently, a similar composite probe has been developed, which utilized the distinguished lifetime with the same emission wavelength to monitor a dynamic biological process [92]. Li et al. designed a $\mathrm{NaYF}_{4}$ : $1 \% \mathrm{Tm} @ \mathrm{NaLuF}_{4}$ and $\mathrm{Rh} 760$ (pH-responsive dye) composite to detect $\mathrm{pH}$. UCNPs and dye molecules could emit luminescence at $800 \mathrm{~nm}$ under the $690 \mathrm{~nm}$ excitation, and the lifetimes were $695 \mu$ s and 1.40 ns, respectively. Moreover, the $\mathrm{pH}$ variation has a negligible effect on the lifetime in $\mathrm{NaYF}_{4}: 1 \% \mathrm{Tm} @ \mathrm{NaLuF}_{4}$ nanoparticles, but has a significant impact on the lifetime of Rh760. The time-gated technology could collect the long lifetime (UCNPs at $800 \mathrm{~nm}$ ), while the short lifetime (Rh760 at $800 \mathrm{~nm}$, only the level of ns) was blocked. Utilizing the time-gated sensing method, they developed a ratio signal of $F_{\text {steady-state }} / F_{\text {time-gated }}$ to detect $\mathrm{pH}$. For example, they could sensitively monitor the $\mathrm{pH}$ value variation from 1.51 to 7.00 in 96-well plates covered with pork tissue, and proved the ratiometric lifetime was reversible and independent of nanoprobe concentration and excitation power density. Similarly, they successfully monitored the gastrointestinal $\mathrm{pH}$ value changes in in vivo experiments (Figure 13a) [93]. 
(a)

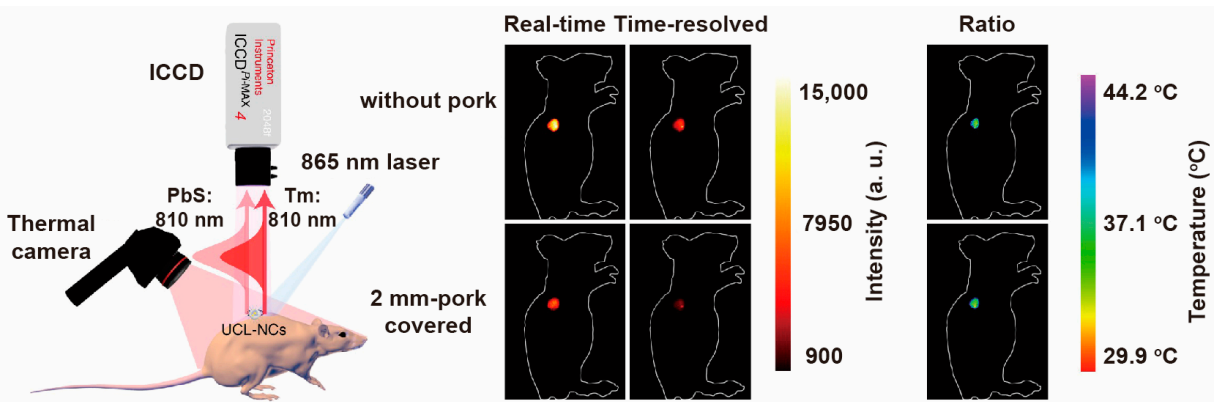

(b)
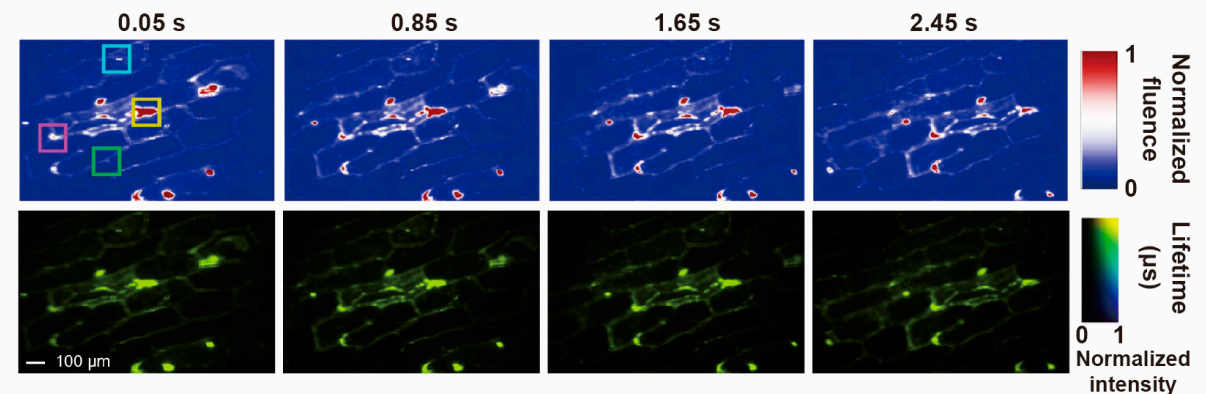

(c)
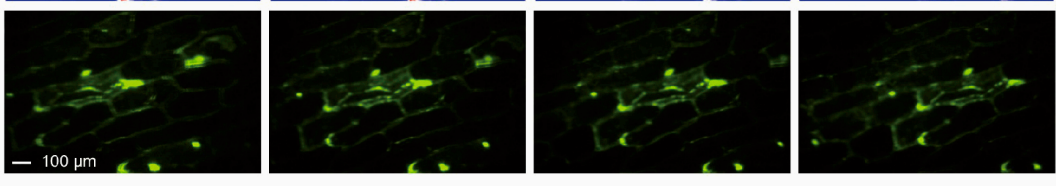
intensity
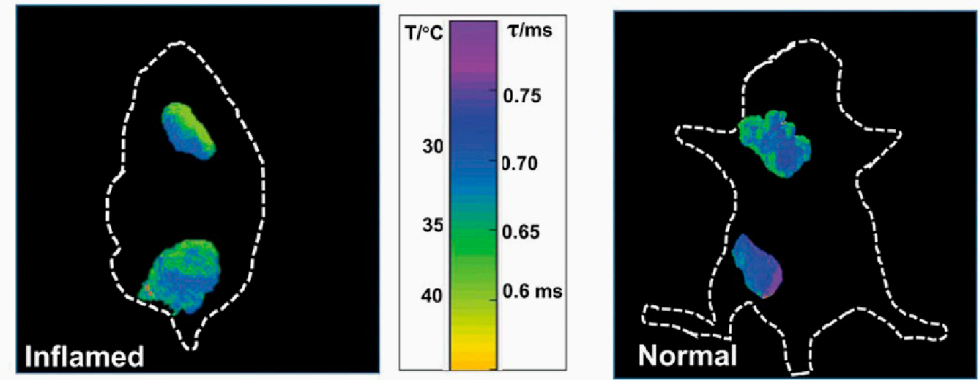

Figure 12. (a) Diagram of surficial and intratumoral detection in vivo and corresponding real-time, time-resolved and ratio UCL imaging without and with a $2 \mathrm{~mm}$-pork slice covering under $865 \mathrm{~nm}$ excitation. Reproduced with permission from [89]. Copyright 2020, Nature Publishing Group. (b) The time-integrated images of a dynamic onion epidermis cell sample with labeling UCNPs. Reproduced with permission from [90]. Copyright 2021, Nature Publishing Group. (c) Thermographic lifetime imaging of the nanosensors in the inflamed and normal mouse, showing the precise position of temperature distribution. Reproduced with permission from [66]. Copyright 2020, WILEY-VCH.

Designing an NIR lifetime $(\tau)$ probe $(900-1700 \mathrm{~nm})$ with different $\mathrm{pH}$-responsive lifetimes is a synthetic challenge. Recently, Zhang et al. designed $\mathrm{Yb}^{3+}$ porphyrinate $(\mathrm{F}-\mathrm{Yb})$ as a $\mathrm{pH}$-sensitive molecular probe. NIR emission and lifetime of $\mathrm{Yb}^{3+}$ increased with $\mathrm{pKa}$ values of ca. 6.6 from $\mathrm{pH} 9.0$ and 5.0. The lifetime at $1000 \mathrm{~nm}$ was prolonged from $135 \mu \mathrm{s}$ to $170 \mu \mathrm{s}$ with $\mathrm{pH}$ from 5.0 to 1.0 due to reduced exposure to water and aggregation. Oral gavage experiments in nude mice were performed through the NIR $\tau$ probe F-Yb for in vivo $\mathrm{pH}$ detection. The lifetime of F-Yb in the stomach is $170 \mu$ s and that in the intestine is $110 \mu \mathrm{s}$. The $\mathrm{pH}$ values were 1.5 and 6.0 in the stomach and intestine, respectively. As a result, different organs could be distinguished with quantitative readouts by using the NIR $\tau$ probe $\mathrm{F}-\mathrm{Yb}$ in time-resolved fluorescence lifetime imaging (Figure 13b) [94]. 
(a)
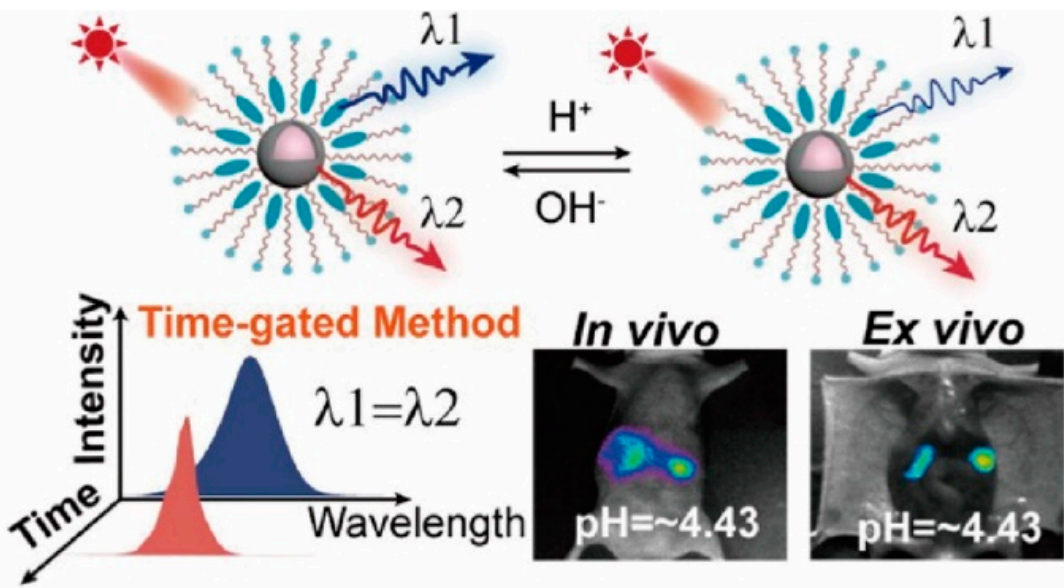

(b)
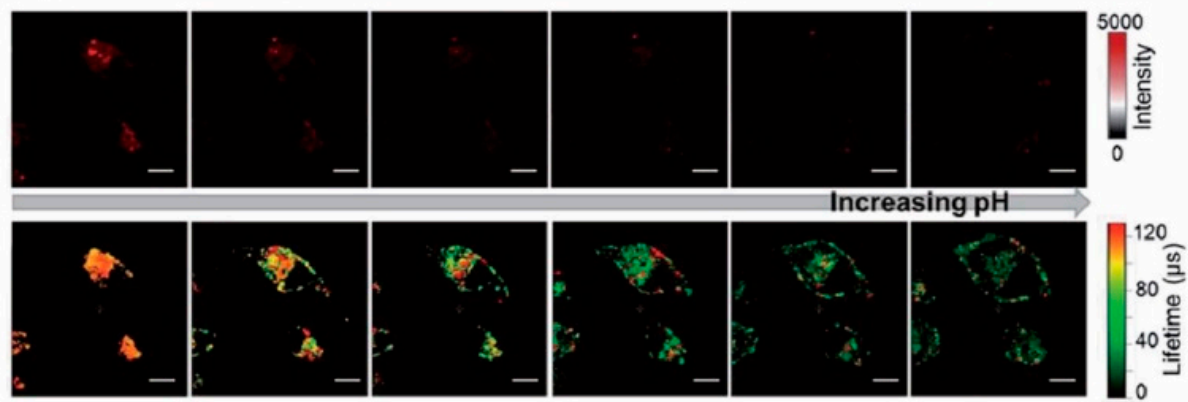

Figure 13. (a) The schematic representation and mechanism of the composite probe reversibly responds to variation in the microenvironment and emits two luminescence emissions with different lifetimes. The images of the gastrointestinal area with different $\mathrm{pH}$ values in vivo or ex vivo. Reproduced with permission from [93]. Copyright 2020, American Chemical Society. (b) The confocal luminescence images (top) and time-resolved luminescence lifetime images (bottom) of F-Yb (10 $\mu \mathrm{M}$, $4 \mathrm{~h}$ ) in HeLa cells reacted with $0.5 \mu \mathrm{M}$ chloroquine. Reproduced with permission from [94]. Copyright 2019, Royal Society of Chemistry.

\section{Conclusions and Outlooks}

Compared with traditional fluorescence detection, lifetime sensing based on the lanthanide nanomaterials is not susceptible to tissue thickness, laser power intensity, background interference and solution concentration. Furthermore, the signal can be enhanced by methods such as time-gated lifetime imaging, ratiometric detection and lifetime-coded technology. While the strategies based on measuring the lifetime signal changes in lanthanidedoped nanomaterial for biodetection and bioimaging have promising prospects, there exist many technical challenges to be overcome in practical application. For example, the nanoprobes' luminescence intensity should be further increased to improve the lifetime signal acquisition speed. It can be solved by optimizing the concentration of dopant, core-shell structure and antenna addition. Moreover, it is highly desirable to increase the stability in the biological microenvironment. Numerous composite nanoprobes consist of lanthanide nanoparticles and molecules such as dye, fluorescein, etc., which are susceptive to their surroundings. Hence, it is necessary to develop stable nanoprobes and measurement techniques. Last but not least, the use of lifetime-based sensing technology could be extended to develop multimodality nanoplatforms with synergistic effects for diagnosis and treatment [95]. This technology will draw wider attention to the development trajectory of fundamental research and clinical applications in luminescent materials. 


\begin{abstract}
Author Contributions: Conceptualization, Q.S.; validation, Q.S. and C.H.; investigation, M.W.; writing-original draft preparation, M.W.; writing-review and editing, Q.S. and C.H.; supervision, Q.S. and C.H. All authors have read and agreed to the published version of the manuscript.
\end{abstract}

Funding: This research was funded by the National Natural Science Foundation of China (Nos. 82002893 and 21701109) for financial supports.

Institutional Review Board Statement: Not applicable.

Informed Consent Statement: Not applicable.

Data Availability Statement: Data are contained within the article.

Conflicts of Interest: The authors declare no conflict of interest.

\title{
References
}

1. Seaberg, J.; Montazerian, H.; Hossen, M.N.; Bhattacharya, R.; Khademhosseini, A.; Mukherjee, P. Hybrid Nanosystems for Biomedical Applications. ACS Nano 2021, 15, 2099-2142. [CrossRef] [PubMed]

2. $\quad$ Liu, X.; Braun, G.B.; Qin, M.; Ruoslahti, E.; Sugahara, K.N. In Vivo Cation Exchange in Quantum Dots for Tumor-specific Imaging. Nat. Commun. 2017, 8, 343. [CrossRef] [PubMed]

3. Liu, Q.; Zhang, Y.; Peng, C.S.; Yang, T.; Joubert, L.-M.; Chu, S. Single Upconversion Nanoparticle Imaging at Sub-10 W $\mathrm{cm}^{-2}$ Irradiance. Nat. Photon. 2018, 12, 548-553. [CrossRef] [PubMed]

4. Chen, S.; Xiong, C.; Liu, H.; Wan, Q.; Hou, J.; He, Q.; Badu-Tawiah, A.; Nie, Z. Mass Spectrometry Imaging Reveals the Sub-organ Distribution of Carbon Nanomaterials. Nat. Nanotechnol. 2015, 10, 176-182. [CrossRef] [PubMed]

5. Swallow, J.G.; Kim, J.J.; Maloney, J.M.; Chen, D.; Smith, J.F.; Bishop, S.R.; Tuller, H.L.; Van Vliet, K.J. Dynamic Chemical Expansion of Thin-film Non-stoichiometric Oxides at Extreme Temperatures. Nat. Mater. 2017, 16, 749-754. [CrossRef] [PubMed]

6. Adhikari, G.C.; Vargas, P.A.; Zhu, H.; Grigoriev, A.; Zhu, P. Tetradic Phosphor White Light with Variable CCT and Superlative CRI through Organolead Halide Perovskite Nanocrystals. Nanoscale Adv. 2019, 1, 1791-1798. [CrossRef]

7. Liu, Y.; Wang, Y.; Song, S.; Zhang, H. Tumor Diagnosis and Therapy Mediated by Metal Phosphorus-Based Nanomaterials. Adv. Mater. 2021, 33, 2103936. [CrossRef]

8. Zhang, K.; Gao, Y.-J.; Yang, P.-P.; Qi, G.-B.; Zhang, J.-P.; Wang, L.; Wang, H. Self-Assembled Fluorescent Organic Nanomaterials for Biomedical Imaging. Adv. Healthc. Mater. 2018, 7, 1800344. [CrossRef]

9. Zhu, X.; Li, J.; Qiu, X.; Liu, Y.; Feng, W.; Li, F. Upconversion Nanocomposite for Programming Combination Cancer Therapy by Precise Control of Microscopic Temperature. Nat. Commun. 2018, 9, 2176. [CrossRef]

10. Qiu, X.; Zhu, X.; Su, X.; Xu, M.; Yuan, W.; Liu, Q.; Xue, M.; Liu, Y.; Feng, W.; Li, F. Near-Infrared Upconversion Luminescence and Bioimaging In Vivo Based on Quantum Dots. Adv. Sci. 2019, 6, 1801834. [CrossRef]

11. Zhu, X.; Su, Q.; Feng, W.; Li, F. Anti-Stokes Shift Luminescent Materials for Bio-applications. Chem. Soc. Rev. 2017, 46, 1025-1039. [CrossRef] [PubMed]

12. Li, Y.; Sun, Y.; Li, J.; Su, Q.; Yuan, W.; Dai, Y.; Han, C.; Wang, Q.; Feng, W.; Li, F. Ultrasensitive Near-Infrared FluorescenceEnhanced Probe for In Vivo Nitroreductase Imaging. J. Am. Chem. Soc. 2015, 137, 6407-6416. [CrossRef]

13. Bünzli, J.-C.G. Lanthanide Luminescence for Biomedical Analyses and Imaging. Chem. Rev. 2010, 110, 2729-2755. [CrossRef] [PubMed]

14. Richardson, D.S.; Lichtman, J.W. Clarifying Tissue Clearing. Cell 2015, 162, 246-257. [CrossRef] [PubMed]

15. Zebibula, A.; Alifu, N.; Xia, L.; Sun, C.; Yu, X.; Xue, D.; Liu, L.; Li, G.; Qian, J. Ultrastable and Biocompatible NIR-II Quantum Dots for Functional Bioimaging. Adv. Funct. Mater. 2018, 28, 1703451. [CrossRef]

16. Thor, W.; Wu, Y.; Wang, L.; Zhang, Y.; Tanner, P.A.; Wong, K.-L. Charging and Ultralong Phosphorescence of Lanthanide Facilitated Organic Complex. Nat. Commun. 2021, 12, 6532. [CrossRef] [PubMed]

17. Suhling, K.; French, P.M.W.; Phillips, D. Time-resolved Fluorescence Microscopy. Photoch. Photobio. Sci. 2005, 4, 13-22. [CrossRef] [PubMed]

18. Zhang, K.Y.; Yu, Q.; Wei, H.; Liu, S.; Zhao, Q.; Huang, W. Long-Lived Emissive Probes for Time-Resolved Photoluminescence Bioimaging and Biosensing. Chem. Rev. 2018, 118, 1770-1839. [CrossRef]

19. Xie, Y.; Arno, M.C.; Husband, J.T.; Torrent-Sucarrat, M.; O'Reilly, R.K. Manipulating the Fluorescence Lifetime at the Sub-cellular Scale via Photo-switchable Barcoding. Nat. Commun. 2020, 11, 2460. [CrossRef]

20. Lu, Y.; Zhao, J.; Zhang, R.; Liu, Y.; Liu, D.; Goldys, E.M.; Yang, X.; Xi, P.; Sunna, A.; Lu, J.; et al. Tunable Lifetime Multiplexing Using Luminescent Nanocrystals. Nat. Photon. 2014, 8, 32-36. [CrossRef]

21. Lei, X.; Li, R.; Tu, D.; Shang, X.; Liu, Y.; You, W.; Sun, C.; Zhang, F.; Chen, X. Intense Near-infrared-II Luminescence from NaCeF 4 : $\mathrm{Er} / \mathrm{Yb}$ Nanoprobes for in vitro Bioassay and In Vivo Bioimaging. Chem. Sci. 2018, 9, 4682-4688. [CrossRef] [PubMed]

22. Liu, Y.; Gu, Y.; Yuan, W.; Zhou, X.; Qiu, X.; Kong, M.; Wang, Q.; Feng, W.; Li, F. Quantitative Mapping of Liver Hypoxia in Living Mice Using Time-Resolved Wide-Field Phosphorescence Lifetime Imaging. Adv. Sci. 2020, 7, 1902929. [CrossRef] [PubMed]

23. Zheng, X.; Zhu, X.; Lu, Y.; Zhao, J.; Feng, W.; Jia, G.; Wang, F.; Li, F.; Jin, D. High-Contrast Visualization of Upconversion Luminescence in Mice Using Time-Gating Approach. Anal. Chem. 2016, 88, 3449-3454. [CrossRef] 
24. Ma, Q.; Wang, J.; Li, Z.; Lv, X.; Liang, L.; Yuan, Q. Recent Progress in Time-Resolved Biosensing and Bioimaging Based on Lanthanide-Doped Nanoparticles. Small 2019, 15, 1804969. [CrossRef] [PubMed]

25. Zheng, W.; Tu, D.; Huang, P.; Zhou, S.; Chen, Z.; Chen, X. Time-resolved Luminescent Biosensing Based on Inorganic Lanthanidedoped Nanoprobes. Chem. Commun. 2015, 51, 4129-4143. [CrossRef] [PubMed]

26. Bergstrand, J.; Liu, Q.; Huang, B.; Peng, X.; Würth, C.; Resch-Genger, U.; Zhan, Q.; Widengren, J.; Ågren, H.; Liu, H. On the Decay Time of Upconversion Luminescence. Nanoscale 2019, 11, 4959-4969. [CrossRef] [PubMed]

27. Quinet, P.; Palmeri, P.; Biémont, E.; Li, Z.S.; Zhang, Z.G.; Svanberg, S. Radiative Lifetime Measurements and Transition Probability Calculations in Lanthanide Ions. J. Alloys Compd. 2002, 344, 255-259. [CrossRef]

28. Kong, J.; Shang, X.; Zheng, W.; Chen, X.; Tu, D.; Wang, M.; Song, J.; Qu, J. Revisiting the Luminescence Decay Kinetics of Energy Transfer Upconversion. J. Phys. Chem. Lett. 2020, 11, 3672-3680. [CrossRef]

29. Lauhon, L.J.; Gudiksen, M.S.; Wang, D.; Lieber, C.M. Epitaxial Core-shell and Core-multishell Nanowire Heterostructures. Nature 2002, 420, 57-61. [CrossRef]

30. Hudry, D.; Howard, I.A.; Popescu, R.; Gerthsen, D.; Richards, B.S. Structure-Property Relationships in Lanthanide-Doped Upconverting Nanocrystals: Recent Advances in Understanding Core-Shell Structures. Adv. Mater. 2019, 31, 1900623. [CrossRef]

31. Zhao, J.; Lu, Z.; Yin, Y.; McRae, C.; Piper, J.A.; Dawes, J.M.; Jin, D.; Goldys, E.M. Upconversion Luminescence with Tunable Lifetime in $\mathrm{NaYF}_{4}: \mathrm{Yb}$,Er Nanocrystals: Role of Nanocrystal Size. Nanoscale 2013, 5, 944-952. [CrossRef] [PubMed]

32. Wang, Y.; Deng, R.; Xie, X.; Huang, L.; Liu, X. Nonlinear Spectral and Lifetime Management in Upconversion Nanoparticles by Controlling Energy Distribution. Nanoscale 2016, 8, 6666-6673. [CrossRef]

33. Su, Q.; Han, S.; Xie, X.; Zhu, H.; Chen, H.; Chen, C.-K.; Liu, R.-S.; Chen, X.; Wang, F.; Liu, X. The Effect of Surface Coating on Energy Migration-Mediated Upconversion. J. Am. Chem. Soc. 2012, 134, 20849-20857. [CrossRef] [PubMed]

34. Huang, Z.; Gao, H.; Mao, Y. Understanding the Effect of $\mathrm{Mn}^{2+}$ on $\mathrm{Yb}^{3+} / \mathrm{Er}^{3+}$ Upconversion and Obtaining a Maximum Upconversion Fluorescence Enhancement in Inert-core/active-shell/inert-shell Structures. RSC Adv. 2016, 6, 83321-83327. [CrossRef]

35. Li, Z.; Liu, H.; Wang, R.; Ji, C.; Wei, Y.; Shi, M.; Wang, Y.; Du, Y.; Zhang, Y.; Yuan, Q.; et al. Bioactive Core-Shell CaF 2 Upconversion Nanostructure for Promotion and Visualization of Engineered Bone Reconstruction. ACS Nano 2020, 14, 16085-16095. [CrossRef] [PubMed]

36. Dong, H.; Sun, L.-D.; Li, L.-D.; Si, R.; Liu, R.; Yan, C.-H. Selective Cation Exchange Enabled Growth of Lanthanide Core/Shell Nanoparticles with Dissimilar Structure. J. Am. Chem. Soc. 2017, 139, 18492-18495. [CrossRef] [PubMed]

37. Tan, M.; del Rosal, B.; Zhang, Y.; Martín Rodríguez, E.; Hu, J.; Zhou, Z.; Fan, R.; Ortgies, D.H.; Fernández, N.; Chaves-Coira, I.; et al. Rare-earth-doped Fluoride Nanoparticles with Engineered Long Luminescence Lifetime for Time-gated In Vivo Optical Imaging in the Second Biological Window. Nanoscale 2018, 10, 17771-17780. [CrossRef]

38. Su, Q.; Wei, H.-L.; Liu, Y.; Chen, C.; Guan, M.; Wang, S.; Su, Y.; Wang, H.; Chen, Z.; Jin, D. Six-photon Upconverted Excitation Energy Lock-in for Ultraviolet-C Enhancement. Nat. Commun. 2021, 12, 4367. [CrossRef]

39. Huang, Q.; Ye, W.; Jiao, X.; Yu, L.; Liu, Y.; Liu, X. Efficient Upconversion Fluorescence in $\mathrm{NaYF}_{4}$ : $\mathrm{Yb}^{3+}, \mathrm{Er}^{3+} / \mathrm{mNaYF}_{4} \mathrm{Multilayer}$ core-shell Nanoparticles. J. Alloys Compd. 2018, 763, 216-222. [CrossRef]

40. Gu, Y.; Guo, Z.; Yuan, W.; Kong, M.; Liu, Y.; Liu, Y.; Gao, Y.; Feng, W.; Wang, F.; Zhou, J.; et al. High-sensitivity Imaging of Time-domain Near-infrared Light Transducer. Nat. Photon. 2019, 13, 525-531. [CrossRef]

41. Li, H.; Tan, M.; Wang, X.; Li, F.; Zhang, Y.; Zhao, L.; Yang, C.; Chen, G. Temporal Multiplexed In Vivo Upconversion Imaging. J. Am. Chem. Soc. 2020, 142, 2023-2030. [CrossRef] [PubMed]

42. Zhou, L.; Fan, Y.; Wang, R.; Li, X.; Fan, L.; Zhang, F. High-capacity Upconversion Wavelength and Lifetime Binary Encoding for Multiplexed Biodetection. Angew. Chem. 2018, 130, 13006-13011. [CrossRef]

43. Fan, Y.; Wang, P.; Lu, Y.; Wang, R.; Zhou, L.; Zheng, X.; Li, X.; Piper, J.A.; Zhang, F. Lifetime-engineered NIR-II Nanoparticles Unlock Multiplexed In Vivo Imaging. Nature Nanotechnol. 2018, 13, 941-946. [CrossRef] [PubMed]

44. Bartkowiak, A.; Runowski, M.; Shyichuk, A.; Majewska, M.; Grzyb, T. Tunable Yellow-green Up-conversion Emission and Luminescence Lifetimes in $\mathrm{Yb}^{3+}-\mathrm{Er}^{3+}-\mathrm{Ho}^{3+}$ Multi-doped $\beta-\mathrm{NaLuF}_{4}$ Crystals. J. Alloys Compd. 2019, 793, 96-106. [CrossRef]

45. Siefe, C.; Mehlenbacher, R.D.; Peng, C.S.; Zhang, Y.; Fischer, S.; Lay, A.; McLellan, C.A.; Alivisatos, A.P.; Chu, S.; Dionne, J.A. Sub-20 nm Core-Shell-Shell Nanoparticles for Bright Upconversion and Enhanced Förster Resonant Energy Transfer. J. Am. Chem. Soc. 2019, 141, 16997-17005. [CrossRef]

46. Dong, H.; Sun, L.-D.; Wang, Y.-F.; Xiao, J.-W.; Tu, D.; Chen, X.; Yan, C.-H. Photon Upconversion in $\mathrm{Yb}^{3+}-\mathrm{Tb}^{3+}$ and $\mathrm{Yb}^{3+}-\mathrm{Eu}^{3+}$ Activated Core/shell Nanoparticles with Dual-band Excitation. J. Mater. Chem. C 2016, 4, 4186-4192. [CrossRef]

47. Liu, X.; Chen, Z.H.; Zhang, H.; Fan, Y.; Zhang, F. Independent Luminescent Lifetime and Intensity Tuning of Upconversion Nanoparticles by Gradient Doping for Multiplexed Encoding. Angew. Chem. 2021, 133, 7117-7121. [CrossRef]

48. Zhang, H.; Fan, Y.; Pei, P.; Sun, C.; Lu, L.; Zhang, F. Tm ${ }^{3+}$-Sensitized NIR-II Fluorescent Nanocrystals for In Vivo Information Storage and Decoding. Angew. Chem. Int. Ed. 2019, 58, 10153-10157. [CrossRef]

49. Liu, X.; Yi, Z.; Qin, X.; Liu, H.; Huang, W.; Liu, X. Tuning Long-Lived Mn(II) Upconversion Luminescence through Alkaline-Earth Metal Doping and Energy-Level Tailoring. Adv. Opt. Mater. 2019, 7, 1900519. [CrossRef]

50. Han, X.; Song, E.; Chen, W.; Zhou, Y.; Zhang, Q. Color-tunable Upconversion Luminescence and Prolonged Eu ${ }^{3+}$ Fluorescence Lifetime in Fluoride $\mathrm{KCdF}_{3}: \mathrm{Yb}^{3+}, \mathrm{Mn}^{2+}{ }_{,} \mathrm{Eu}^{3+}$ via Controllable and Efficient Energy Transfer. J. Mater. Chem. C 2020. [CrossRef] 
51. Liu, X.; Wang, Y.; Li, X.; Yi, Z.; Deng, R.; Liang, L.; Xie, X.; Loong, D.T.B.; Song, S.; Fan, D.; et al. Binary Temporal Upconversion Codes of $\mathrm{Mn}^{2+}$-activated Nanoparticles for Multilevel Anti-counterfeiting. Nat. Commun. 2017, 8, 899. [CrossRef]

52. Qin, H.; Wu, D.; Sathian, J.; Xie, X.; Ryan, M.; Xie, F. Tuning the Upconversion Photoluminescence Lifetimes of $\mathrm{NaYF}_{4}$ : $\mathrm{Yb}^{3+}$, $\mathrm{Er}^{3+}$ through Lanthanide $\mathrm{Gd}^{3+}$ Doping. Sci. Rep. 2018, 8, 12683. [CrossRef] [PubMed]

53. Payne, N.C.; Kalyakina, A.S.; Singh, K.; Tye, M.A.; Mazitschek, R. Bright and Stable Luminescent Probes for Target Engagement Profiling in Live Cells. Nat. Chem. Biol. 2021, 17, 1168-1177. [CrossRef] [PubMed]

54. Muhr, V.; Würth, C.; Kraft, M.; Buchner, M.; Baeumner, A.J.; Resch-Genger, U.; Hirsch, T. Particle-Size-Dependent Förster Resonance Energy Transfer from Upconversion Nanoparticles to Organic Dyes. Anal. Chem. 2017, 89, 4868-4874. [CrossRef] [PubMed]

55. Kong, M.; Gu, Y.; Liu, Y.; Shi, Y.; Wu, N.; Feng, W.; Li, F. Luminescence Lifetime-Based In Vivo Detection with Responsive Rare Earth-Dye Nanocomposite. Small 2019, 15, 1904487. [CrossRef]

56. Wang, M.; Wei, H.; Wang, S.; Hu, C.; Su, Q. Dye Sensitization for Ultraviolet Upconversion Enhancement. Nanomaterials 2021, $11,3114$. [CrossRef]

57. Xue, M.; Cao, C.; Zhou, X.; Xu, M.; Feng, W.; Li, F. Tuning the Upconversion Efficiency and Spectrum of Upconversion Nanoparticles through Surface Decorating of an Organic Dye. Inorg. Chem. 2019, 58, 14490-14497. [CrossRef]

58. Lyu, C.; Li, H.; Wyatt, P.B.; Gillin, W.P.; Ye, H. Prolonged and Efficient Near-infrared Photoluminescence of a Sensitized Organic Ytterbium-containing Molecular Composite. J. Mater. Chem. C 2020, 8, 9502-9505. [CrossRef]

59. Xu, H.; Han, S.; Deng, R.; Su, Q.; Wei, Y.; Tang, Y.; Qin, X.; Liu, X. Anomalous Upconversion Amplification Induced by Surface Reconstruction in Lanthanide Sublattices. Nat. Photon. 2021, 15, 732-737. [CrossRef]

60. Singh, N.S.; Ningthoujam, R.S.; Yaiphaba, N.; Singh, S.D.; Vatsa, R.K. Lifetime and Quantum Yield Studies of Dy ${ }^{3+}$ Doped GdVO $_{4}$ Nanoparticles: Concentration and Annealing Effect. J. Appl. Phys. 2009, 105, 064303. [CrossRef]

61. Singh, N.S.; Ningthoujam, R.S.; Luwang, M.N.; Singh, S.D.; Vatsa, R.K. Luminescence, Lifetime and Quantum Yield Studies of $\mathrm{YVO}_{4}: \mathrm{Ln}^{3+}\left(\mathrm{Ln}^{3+}=\mathrm{Dy}^{3+}, \mathrm{Eu}^{3+}\right)$ Nanoparticles: Concentration and Annealing Effects. Chem. Phys. Lett. 2009, 480, 237-242. [CrossRef]

62. Yu, W.; Xu, W.; Song, H.; Zhang, S. Temperature-dependent Upconversion Luminescence and Dynamics of $\mathrm{NaYF}_{4}$ : $\mathrm{Yb}^{3+} / \mathrm{Er}^{3+}$ Nanocrystals: Influence of Particle Size and Crystalline Phase. Dalton Trans. 2014, 43, 6139-6147. [CrossRef]

63. Chihara, T.; Umezawa, M.; Miyata, K.; Sekiyama, S.; Hosokawa, N.; Okubo, K.; Kamimura, M.; Soga, K. Biological Deep Temperature Imaging with Fluorescence Lifetime of Rare-Earth-Doped Ceramics Particles in the Second NIR Biological Window. Sci. Rep. 2019, 9, 12806. [CrossRef] [PubMed]

64. Fu, Y.; Zhao, L.; Guo, Y.; Yu, H. Up-conversion Luminescence Lifetime Thermometry Based on the ${ }^{1} \mathrm{G}_{4}$ State of Tm ${ }^{3+}$ Modulated by Cross Relaxation Processes. Dalton Trans. 2019, 48, 16034-16040. [CrossRef] [PubMed]

65. Savchuk, O.A.; Haro-González, P.; Carvajal, J.J.; Jaque, D.; Massons, J.; Aguiló, M.; Díaz, F. Er: Yb: $\mathrm{NaY}_{2} \mathrm{~F}_{5} \mathrm{O}$ up-converting nanoparticles for sub-tissue fluorescence lifetime thermal sensing. Nanoscale 2014, 6, 9727-9733. [CrossRef]

66. Tan, M.; Li, F.; Cao, N.; Li, H.; Wang, X.; Zhang, C.; Jaque, D.; Chen, G. Accurate In Vivo Nanothermometry through NIR-II Lanthanide Luminescence Lifetime. Small 2020, 16, 2004118. [CrossRef]

67. Lu, K.; Yi, Y.; Xu, L.; Sun, X.; Liu, L.; Li, H. Temperature-Independent Lifetime and Thermometer Operated in a Biological Window of Upconverting $\mathrm{NaErF}_{4}$ Nanocrystals. Nanomaterials 2020, 10, 24. [CrossRef]

68. Sun, Y.; Feng, W.; Yang, P.; Huang, C.; Li, F. The Biosafety of Lanthanide Upconversion Nanomaterials. Chem. Soc. Rev. 2015, 44, 1509-1525. [CrossRef]

69. Zhao, M.; Li, B.; Wu, Y.; He, H.; Zhu, X.; Zhang, H.; Dou, C.; Feng, L.; Fan, Y.; Zhang, F. A Tumor-Microenvironment-Responsive Lanthanide-Cyanine FRET Sensor for NIR-II Luminescence-Lifetime in Situ Imaging of Hepatocellular Carcinoma. Adv. Mater. 2020, 32, 2001172. [CrossRef]

70. Lin, Z.-Y.; Qu, Z.-b.; Chen, Z.-H.; Han, X.-Y.; Deng, L.-X.; Luo, Q.; Jin, Z.; Shi, G.; Zhang, M. The Marriage of Protein and Lanthanide: Unveiling a Time-Resolved Fluorescence Sensor Array Regulated by $\mathrm{pH}$ toward High-Throughput Assay of Metal Ions in Biofluids. Anal. Chem. 2019, 91, 11170-11177. [CrossRef]

71. Hanaoka, K.; Kikuchi, K.; Kobayashi, S.; Nagano, T. Time-Resolved Long-Lived Luminescence Imaging Method Employing Luminescent Lanthanide Probes with a New Microscopy System. J. Am. Chem. Soc. 2007, 129, 13502-13509. [CrossRef] [PubMed]

72. Cheng, S.; Shen, B.; Yuan, W.; Zhou, X.; Liu, Q.; Kong, M.; Shi, Y.; Yang, P.; Feng, W.; Li, F. Time-Gated Ratiometric Detection with the Same Working Wavelength to Minimize the Interferences from Photon Attenuation for Accurate In Vivo Detection. ACS Central Sci. 2019, 5, 299-307. [CrossRef]

73. Tian, L.; Ma, H.; Song, B.; Dai, Z.; Zheng, X.; Zhang, R.; Chen, K.; Yuan, J. Time-gated Luminescence Probe for Ratiometric and Luminescence Lifetime Detection of Hypochorous Acid in Lysosomes of Live Cells. Talanta 2020, 212, 120760. [CrossRef] [PubMed]

74. Song, B.; Ye, Z.; Yang, Y.; Ma, H.; Zheng, X.; Jin, D.; Yuan, J. Background-free in-vivo Imaging of Vitamin C Using Time-gateable Responsive Probe. Sci. Rep. 2015, 5, 14194. [CrossRef] [PubMed]

75. Lu, Y.; Lu, J.; Zhao, J.; Cusido, J.; Raymo, F.M.; Yuan, J.; Yang, S.; Leif, R.C.; Huo, Y.; Piper, J.A.; et al. On-the-fly Decoding Luminescence Lifetimes in the Microsecond Region for Lanthanide-encoded Suspension Arrays. Nat. Commun. $2014,5,3741$. [CrossRef] [PubMed] 
76. Mizukami, S.; Tonai, K.; Kaneko, M.; Kikuchi, K. Lanthanide-Based Protease Activity Sensors for Time-Resolved Fluorescence Measurements. J. Am. Chem. Soc. 2008, 130, 14376-14377. [CrossRef]

77. Mizukami, S.; Yamamoto, T.; Yoshimura, A.; Watanabe, S.; Kikuchi, K. Covalent Protein Labeling with a Lanthanide Complex and Its Application to Photoluminescence Lifetime-Based Multicolor Bioimaging. Angew. Chem. Int. Ed. 2011, 50, $8750-8752$. [CrossRef]

78. Vuojola, J.; Syrjänpää, M.; Lamminmäki, U.; Soukka, T. Genetically Encoded Protease Substrate Based on Lanthanide-Binding Peptide for Time-Gated Fluorescence Detection. Anal. Chem. 2013, 85, 1367-1373. [CrossRef]

79. Tu, D.; Liu, L.; Ju, Q.; Liu, Y.; Zhu, H.; Li, R.; Chen, X. Time-Resolved FRET Biosensor Based on Amine-Functionalized Lanthanide-Doped $\mathrm{NaYF}_{4}$ Nanocrystals. Angew. Chem. Int. Ed. 2011, 50, 6306-6310. [CrossRef]

80. Liu, Y.; Zhou, S.; Tu, D.; Chen, Z.; Huang, M.; Zhu, H.; Ma, E.; Chen, X. Amine-Functionalized Lanthanide-Doped Zirconia Nanoparticles: Optical Spectroscopy, Time-Resolved Fluorescence Resonance Energy Transfer Biodetection, and Targeted Imaging. J. Am. Chem. Soc. 2012, 134, 15083-15090. [CrossRef]

81. Zheng, W.; Zhou, S.; Chen, Z.; Hu, P.; Liu, Y.; Tu, D.; Zhu, H.; Li, R.; Huang, M.; Chen, X. Sub-10 nm Lanthanide-doped CaF 2 Nanoprobes for Time-resolved Luminescent Biodetection. Angew. Chem. Int. Ed. 2013, 52, 6671-6676. [CrossRef] [PubMed]

82. Jin, X.; Zeng, Q.; Zheng, J.; Xing, D.; Zhang, T. Aptamer-Functionalized Upconverting Nanoformulations for Light-Switching Cancer-Specific Recognition and in Situ Photodynamic-Chemo Sequential Theranostics. ACS Appl. Mater. Inter. 2021, 13, 9316-9328. [CrossRef]

83. Xu, Y.; Li, Q. Multiple Fluorescent Labeling of Silica Nanoparticles with Lanthanide Chelates for Highly Sensitive Time-Resolved Immunofluorometric Assays. Clin. Chem. 2007, 53, 1503-1510. [CrossRef] [PubMed]

84. Lu, J.; Martin, J.; Lu, Y.; Zhao, J.; Yuan, J.; Ostrowski, M.; Paulsen, I.; Piper, J.A.; Jin, D. Resolving Low-Expression Cell Surface Antigens by Time-Gated Orthogonal Scanning Automated Microscopy. Anal. Chem. 2012, 84, 9674-9678. [CrossRef] [PubMed]

85. Guo, H.; Song, X.; Lei, W.; He, C.; You, W.; Lin, Q.; Zhou, S.; Chen, X.; Chen, Z. Direct Detection of Circulating Tumor Cells in Whole Blood Using Time-Resolved Luminescent Lanthanide Nanoprobes. Angew. Chem. Int. Ed. 2019, 58, 12195-12199. [CrossRef]

86. Sayyadi, N.; Justiniano, I.; Connally, R.E.; Zhang, R.; Shi, B.; Kautto, L.; Everest-Dass, A.V.; Yuan, J.; Walsh, B.J.; Jin, D.; et al. Sensitive Time-Gated Immunoluminescence Detection of Prostate Cancer Cells Using a TEGylated Europium Ligand. Anal. Chem. 2016, 88, 9564-9571. [CrossRef]

87. Zhu, X.; Liu, X.; Zhang, H.; Zhao, M.; Pei, P.; Chen, Y.; Yang, Y.; Lu, L.; Yu, P.; Sun, C.; et al. High-Fidelity NIR-II Multiplexed Lifetime Bioimaging with Bright Double Interfaced Lanthanide Nanoparticles. Angew. Chem. Int. Ed. 2021, 60, 23545-23551. [CrossRef]

88. Siaï, A.; Haro-González, P.; Horchani-Naifer, K.; Férid, M. $\mathrm{La}_{2} \mathrm{O}_{3}$ : Tm, Yb, Er upconverting nano-oxides for sub-tissue lifetime thermal sensing. Sens. Actuat. B-Chem. 2016, 234, 541-548. [CrossRef]

89. Qiu, X.; Zhou, Q.; Zhu, X.; Wu, Z.; Feng, W.; Li, F. Ratiometric Upconversion Nanothermometry with Dual Emission at the Same Wavelength Decoded via a Time-resolved Technique. Nat. Commun. 2020, 11, 4. [CrossRef]

90. Liu, X.; Skripka, A.; Lai, Y.; Jiang, C.; Liu, J.; Vetrone, F.; Liang, J. Fast Wide-field Upconversion Luminescence Lifetime Thermometry Enabled by Single-shot Compressed Ultrahigh-speed Imaging. Nat. Commun. 2021, 12, 6401. [CrossRef]

91. Kong, M.; Gu, Y.; Chai, Y.; Ke, J.; Liu, Y.; Xu, X.; Li, Z.; Feng, W.; Li, F. Luminescence Interference-free Lifetime Nanothermometry Pinpoints In Vivo Temperature. Sci. China Chem. 2021, 64, 974-984. [CrossRef]

92. Estebanez, N.; Ferrera-González, J.; Cortez-Cevallos, I.A.; González-Béjar, M.; Pérez-Prieto, J. Lengthening the Lifetime of Common Emissive Probes to Microseconds by a Jigsaw-Like Construction of NIR-Responsive Nanohybrids. Adv. Opt. Mater. 2020, 8, 1902030. [CrossRef]

93. Cheng, S.; Liu, Q.; Zhou, X.; Gu, Y.; Yuan, W.; Feng, W.; Li, F. Reversible Ratiometric Probe Combined with the Time-Gated Method for Accurate In Vivo Gastrointestinal pH Sensing. ACS Appl. Mater. Inter. 2020, 12, 25557-25564. [CrossRef] [PubMed]

94. Ning, Y.; Cheng, S.; Wang, J.-X.; Liu, Y.-W.; Feng, W.; Li, F.; Zhang, J.-L. Fluorescence Lifetime Imaging of Upper Gastrointestinal pH In Vivo with a Lanthanide Based Near-infrared $\tau$ Probe. Chem. Sci. 2019, 10, 4227-4235. [CrossRef] [PubMed]

95. Ang, J.; Yoon, J.; Zhou, M.; Wei, H.-L.; Goh, Y.; Lok, K.; Liu, Y.; Li, Z.; Wang, H.; Su, Q.; et al. Deciphering Nanoparticle Trafficking into Glioblastomas Uncovers an Augmented Antitumor Effect of Metronomic Chemotherapy. Adv. Mater. 2022, $34,2106194$. [CrossRef] 